\title{
Archives of
}

\section{Business Administration and Management}

\section{Impact of Property Rights and Regulations on Agrarian Sustainability in Bulgaria}

\author{
Hrabrin Bachev* \\ Institute of Agricultural Economics, Sofia, Bulgaria
}

"Corresponding author: Hrabrin Bachev, Institute of Agricultural Economics, Sofia, Bulgaria. Tel: +35924651128; Email: hbachev@yahoo.com

Citation: Bachev H (2018) Impact of Property Rights and Regulations on Agrarian Sustainability in Bulgaria. Arch Bus Adm Manag: ABAM-112. DOI: 10.29011/ABAM-112. 100012

Received Date: 10 July, 2018; Accepted Date: 19 July, 2018; Published Date: 30 July, 2018

\begin{abstract}
The specific system of formal and informal property rights and regulations is a critical factor, which to a great extent (pre) determines the type and speed of development in different countries, industries, regions, communities, etc. This article tries to fill the gap and assesses the impact of institutional environment on agrarian sustainability in Bulgaria. The interdisciplinary New Institutional Economics framework is applied and assessment made on specific effects of major components of the "external" institutional environment on agrarian sustainability level in different administrative, geographical and ecological regions, subsectors of agriculture, and farms of various juridical type and size. Our study has found out that individual elements of external institutional, market and natural environment affect quite unequally farms of different types, individual subsectors of agriculture, and specific ecological and geographical regions. This type of studies is to be expended and their precision and representation increased. The latter however, requires a close cooperation between all interested parties, and participation of the farmers, agrarian organizations, local and central authorities, interest groups, research institutes and experts, etc.
\end{abstract}

Keywords: Agrarian sustainability; Bulgaria; Governance; Institutional; Market; Natural environment

JEL: Q13, Q12, Q18, D23, E61, H23, L14, L22, L33, L51

\section{Introduction}

The specific system of governance is a critical factor, which to a great extent (pre)determines the type and the speed of development of different countries, industries, regions, communities, etc. [1,2]. Having in mind the importance of the agrarian sector (in terms of employed resources, contribution to individuals and social welfare, positive and/or negative impacts on environment, etc.), the assessment and the improvement of the governance of agrarian sustainability is among the most topical theoretical and practical issues at contemporary stage [3-11].

Despite that however, with a very few exceptions [3,12-26] still there are no sufficient comprehensive empirical studies on the impact of institutional, market and natural environment on agrarian sustainability in Bulgaria and abroad. The latter is a consequence of the "newness" of that problem, the lack of statistical and other information, inadequacy of the traditional economic modes of analysis in that area, etc. Subsequently, the economic analyses do not give a full insight on "driving" factors of socio-economic development, and possibility to effectively assist public policy, and individual and collective actions for sustainable development.

This article applies the interdisciplinary New Institutional Economics (combining Economics, Organization, Sociology, Law, Political and Behavioral Sciences), and assesses the impact of institutional, market and natural environment on agrarian sustainability in Bulgaria.

\section{New Institutional Economic Framework}

Maintaining the social, economic and environmental functions of agriculture requires an effective social order (a "good governance") - a system mechanisms and forms regulating, coordinating, stimulating, and controlling the behaviors, actions 
and relations of individual agents at different levels 3 . The system of governance of agrarian sustainability is a part of the specific system of agrarian governance and includes: diverse agrarian (farm managers, resource owners, hired labor) and non-agrarian (agrarian and related business, consumers, residents of rural area, interests groups, agrarian administration) agents, and a variety of mechanisms and forms for governing of behavior, activity, relations, and impacts of related agents.

The system of governance of agrarian sustainability includes a number of principle mechanisms and modes, which manage the behavior and actions of individual agents, and eventually predetermine the level of agrarian sustainability including (Figure $1)$ :

$>$ institutional environment ("rules of the game") - that is the distribution of formal and informal rights and obligations between individuals, groups, and generations, and the system(s) of enforcement of these rights and rules (1);

$>$ market modes ("invisible hand of market") - those are various decentralized initiatives governed by the free market price movements and market competition;

$>$ private modes ("private or collective order") - diverse private initiatives, and special contractual and organizational arrangements;

$>$ public modes ("public order") - those are various forms of public (community, state, international) interventions in the market and private sector such as: public guidance, regulation, assistance, taxation, funding, provision, modernization of property rights and rules, etc.;

$>$ hybrid forms - some combination of the above three like public-private partnership, etc.

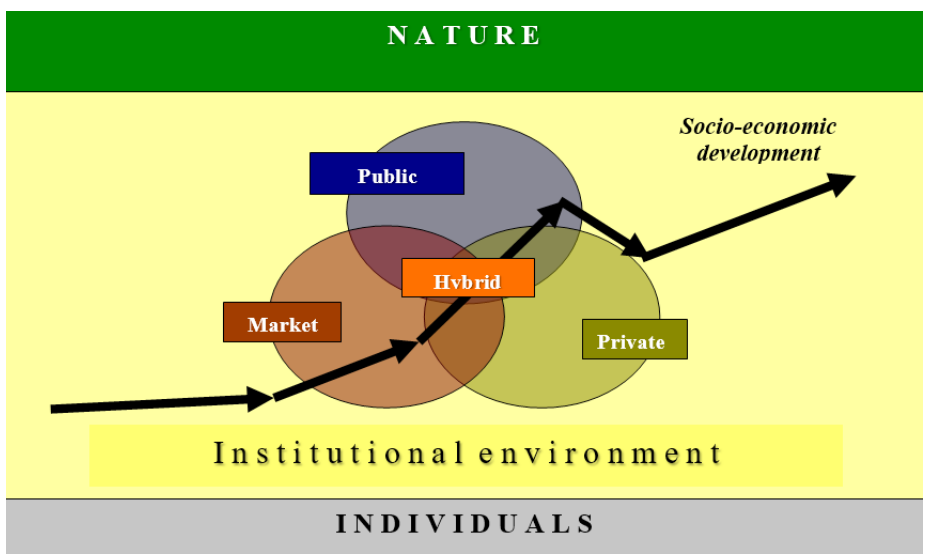

Figure 1: System of governance of agrarian sustainability.

Institutional development is initiated by the public (state, community) authorities, international actions (agreements, assistance, pressure), and private and collective actions of individuals. It is associated with the modernization and/or redistribution of existing rights, and evolution of new rights and novel (private, public, hybrid) institutions for their enforcement. For instance, the European Union (EU) membership of Bulgaria is associated with adaptation of the modern European legislation (Acquis Communautaire) as well as better enforcement of the entire system of laws and standards for quality, labor, social protection, environment conservation, animal welfare, etc. At current stage many of the institutional innovations are also results of the pressure and initiatives of certain interests groups - ecoassociations, consumer organizations, etc.

Institutional environment creates unequal incentives, restrictions, costs, and impacts for different aspects of agrarian sustainability, and in the long run (pre)determines the type and character of agrarian development. Efficiency of the specific system of governance of agrarian sustainability eventually finds expression in certain level and dynamics of the social, economic, and environmental sustainability of agriculture [3,5]. Accordingly, a high or increasing agrarian sustainability means a high efficiency of the system of governance, and vice versa. The agrarian sustainability and its individual aspects have multiple dimensions. Therefore, in order to assess the efficiency of the governance it is necessary to work out an adequate system for assessing the social, economic, environmental, and integral sustainability of agriculture $[5,6]$.

Agricultural producers (farms) are major agents in the system of governance of agrarian sustainability. For identification of the specific modes of governance of agrarian sustainability in Bulgaria and in different regions of the country, subsectors of agriculture, types of agro-ecosystems, as well as sustainability contribution of the farms of different juridical type and size, in 2017 in-depth interviews were carried out with managers of 40 farms of different kind and location. For identification of the "typical" for a particular region agricultural farms an assistance is used of the major producers associations, state agencies, processors, bio-certifying and servicing organizations, and local authorities. The structure and the specific features of the surveyed farms approximately correspond to the real structure of all farms in the studied regions of the country.

The survey comprises multiple questions associated with the impact of major elements of socio-economic, institutional and natural environment on socio-economic, environmental, and integral sustainability of surveyed holdings. Initially the managers assessed the impact of each component of the institutional environment as "positive", "neutral", or "negative". After that, the relations between the "estimates of managers" for the impacts of the elements of external environment and the sustainability level of respective farms are specified. The framework applied for assessing 
the socio-economic, environmental and integral sustainability level is presented in details in another publication [6]. The integral estimates are arithmetic averages of the assessments of individual farms of a particular type.

\section{Institutional Impact on Agrarian Sustainability}

Provided and well protected by the existing institutional arrangements private rights on diverse agrarian resources (farmlands, pastures and meadows, material and intellectual assets, water sources, ecosystems, etc.) are important factors for effective exploitation of resources and sustainable development. Our survey have proved that, for the majority of interviewed agricultural producers $(37,5 \%)$ "provided rights on agrarian resources and the costs for protection of private rights" have a positive impact on multiple aspects of agrarian sustainability (Figure 2).

According to the majority of the farmers existing private rights and costs for their protection are of a primary importance for the improvement of economic sustainability. The system of private property rights has a high economic significance since it creates incentives for investment and effective utilization of resources. What is more, for many managers dominating structure of rights and rules in the sectors, modernized according to the EU standards, impact positively social and environmental aspects of agrarian sustainability as well. Furthermore, for almost every third of the surveyed farms existing private rights on agrarian resources and (a high) level of costs for their protection and exchange affect rather negatively different aspects of agrarian sustainability. One of the interviewed points out that managed by him farmlands is situated in 500 different locations with distance between individual plots up to $30 \mathrm{~km}$. Besides great transportation costs that farm also has a high cost for governance, protection of property and yield, application for public subsidies and other relations with authorities. For instance, in order to submit numerous (1500) applications in the municipality office, the farmer has to bring own papers and toners for printing out applications.

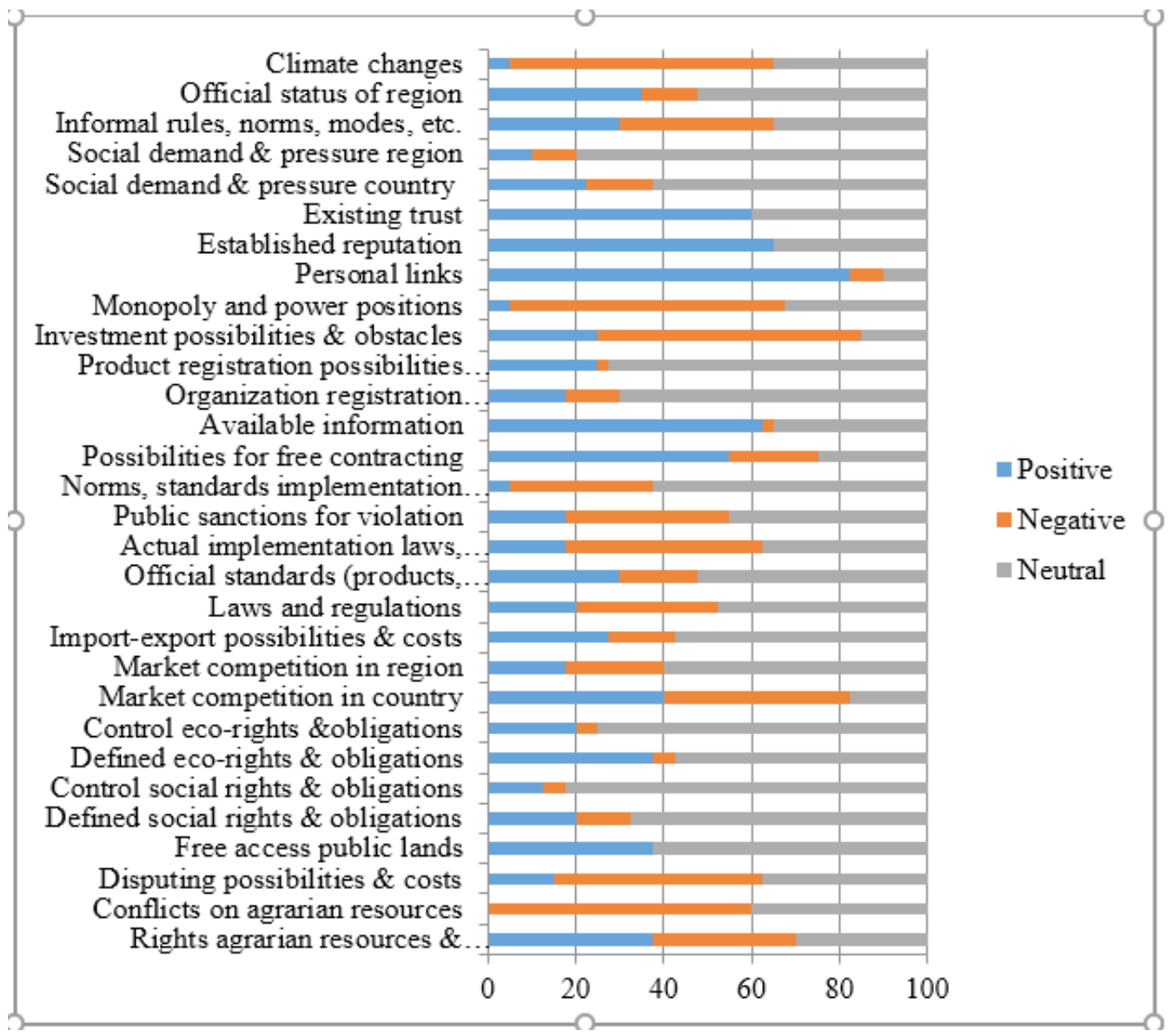

Figure 2: Impact of major elements of socio-economic, institutional and natural environment on agrarian sustainability (percent). Source: Interviews with managers of farms, 2017. 
The negative impact of the structure and the costs, associated with rights on agrarian resources, affects farms of various types (Figure 3). The only exceptions are holdings specialized in Vegetables, Flowers, and Mushrooms, Pigs, Poultries, and Rabbits, and Mix livestock, as well as those located in Less-favored non-mountainous regions. All these farms usually use smaller amount of own or rented lands (greenhouse vegetable production, pig production, middle size holdings), have access to usage of public meadows and pastures (grazing livestock) and no need to trade (purchase or lease) of agricultural lands in large amount or other intellectual agrarian products (origins, new crop varieties and technologies, etc.).

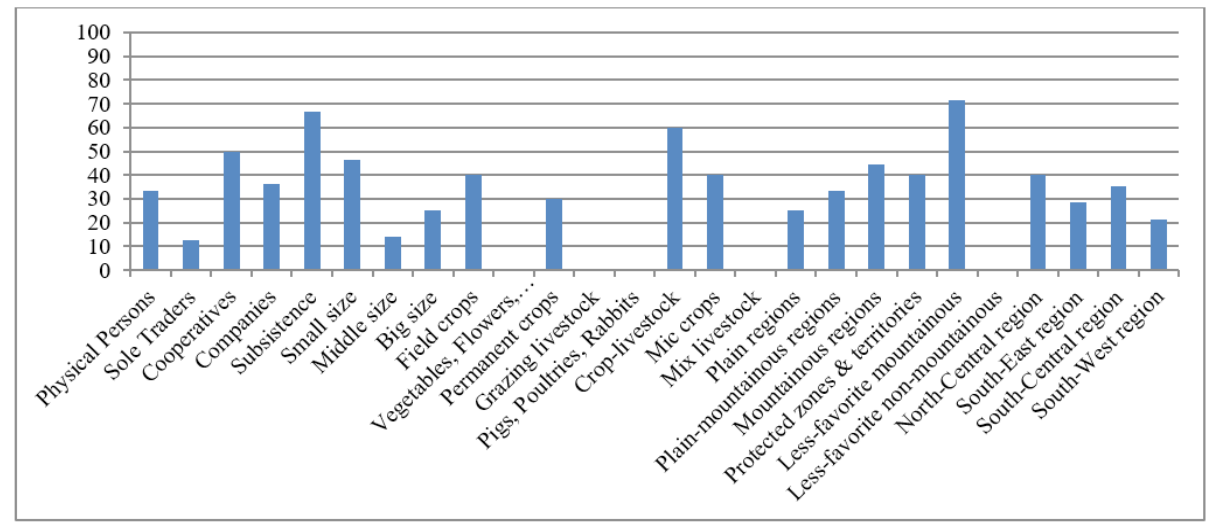

Figure 3: Negative impact of provided rights on agrarian resources and costs for protection of private rights on agrarian sustainability in Bulgaria (percent). Source: Interviews with managers of farms, 2017.

On the other hand, holdings, implementing intensive deals (purchases, leases) of farmlands with numerous land owners for an effective exploration of scales and scopes, or using ownership as a collateral for loan, to a bigger extent are affected by the negative consequences of imperfect institutional framework (identification of property rights) and costs for protection and transfer of private rights. For example, a half of the Cooperatives, $60 \%$ of holdings in Mix crop-livestock, $40 \%$ of farms in Field crops and Mix crops, underline the negative impact of that factor.

Many cases are reported, when for producers is difficult to organize efficient operations on larger land plots, due to practical impossibility to negotiate lease-in or purchase of dispersed small plots of landlords - lack of formal ownership titles, many heirs, absence from the country, disputes with a third party, enormous costs, etc. One of the surveyed farm, representing a big for the region investor in vine operation, points out the existence of numerous little "islands" of (fragmented, unidentified, multiple owners, etc.) land property in the area for expansion of enterprise. All these land plots are practically impossible to acquire and that impedes planned effective enlargement of the production in that farm.

That restricting element of the institutional environment is particularly critical for farms with smaller sizes $(46,67 \%)$, having no potential (negotiation power, sufficient staff, access to lawyers, etc.) typical for the large business enterprises. Some smaller farms and semi-market holdings report for discrepancy in the description and borders in the formal ownership documents with the actual sizes and locations of the property (lands, buildings, etc.) also preventing the effective investments and deals. Identification of the ownership rights and correction of documentary mistakes from the past through bureaucratic and court procedures, is a long, costly, and inaccessible for many (small) producers process. The latter is a consequence of the existence of many and/or lack of any heirs, numerous interested parties, high costs for expertise, lawyers, lawsuits, introduction into new ownership, etc. The adverse impact on sustainability of that factor is particularly strong for semimarket holdings - two-third of surveyed farms Predominantly for subsistence.

The negative impact of existing structure and possibilities for protection of private property rights is particularly strong for holdings in Mountainous regions (44,44\%), where agrarian resources are limited and dislocate in large areas. Also, a good part of the farms in Less-favored mountainous regions (71,43\%) and those with Lands in protected zones and territories (40\%) are influenced by the negative impact of that component of institutional environment due to multiple restrictions of/for utilization of resources related with the (special) status of such areas.

Many producers of different type also report having high costs for protection of resources and output, due to constant thefts of property and yields. A good number of holdings provide permanent security for yield, which additionally make product more expensive or turn managers, owners and their families into guards. According to a surveyed strawberry producer, he and his farther spend 24 hours on the field during ripening of fruits. Another 
surveyed producer shares experience in which in order to protect the property from repeated thieves he had built an expensive fence around, and subsequently the valuable fence was stolen. A president of the surveyed cooperative also underlines that problem and the fact, that after he terminate "work" in the office, he "becomes a guard, since the municipality does not secure needed protection of the fields". The multiple complains of the latter manager against "well known" thieves, are not resolved by the authorities "since harms were too small to be punished". Because of the same reason, in the South-East region of the country it is not produced corn of big farmers at all (easy to steal). Another cooperative in that region regularly hires security guards for protection of the property in the farmyard and the grape yields.

There are also many examples, when private animals destroy harvest of other farmers and it is very difficult to punish offenders, due to uncertainty, or difficulty to prove and claim through lawful way. In other instances, wild animals destroy sow, permanent crops and/or yield, and for assault on property is not by persons, but there is needs (costs) for managing natural risk (purchase of insurance, building fence, payment for security guards, etc.). For almost $30 \%$ of surveyed farms the rights on agrarian resources and the costs for their protection have no importance (neutrality) in relation to aspects of agrarian sustainability. The latter means, that existing system of governance, and concentration, transfer and protection of agrarian resources in these holdings "work well" and do not prevent strategies and activities for sustainable development.

The character, strength, and possibility for rapid and costless resolution of conflicts, associated with the rights on agrarian resources, are important factor for effective governance of agrarian sustainability. For $60 \%$ of the surveyed farms "existing conflicts over agrarian resources" impact negatively diverse aspects of agrarian sustainability, while for the rest part they are not essential (Figure 2). The conflicts usually obstruct efficient distribution and sustainable exploitation of agrarian resources, and are related with significant costs for prevention and resolution. According to the managers of surveyed holdings, that factor, most often considerably diminish economic sustainability, sometimes environmental sustainability, and occasionally social sustainability in the sector.

Conflicts of various types, associated with agrarian resources, have unequal effect on sustainability of different subsectors, regions, and type of farming organizations (Figure 4). Such conflicts are commonly associated with the strong interests for acquisition of ownership and/or utilization of certain limited (valuable) agrarian resources by two or more parties - individual agents, farms, related and unrelated businesses, powerful groups, etc. In certain cases there are strong conflicts, related to strategies of some large groups for "legitimate" acquisition of major resources (lands, processing facilities, entire enterprises) from smaller producers through various schemes (applying pressure, unfair competition, severe conditions for crediting, lawsuits and bankruptcy). There are many instances of conflicts, caused by not defined or badly defined rights of ownership, direction, utilization etc. of certain resources or by their "public" (good) character, as it is for the new technologies, state and municipal pastures and lands, water sources, ecosystem services, critical infrastructure, etc.

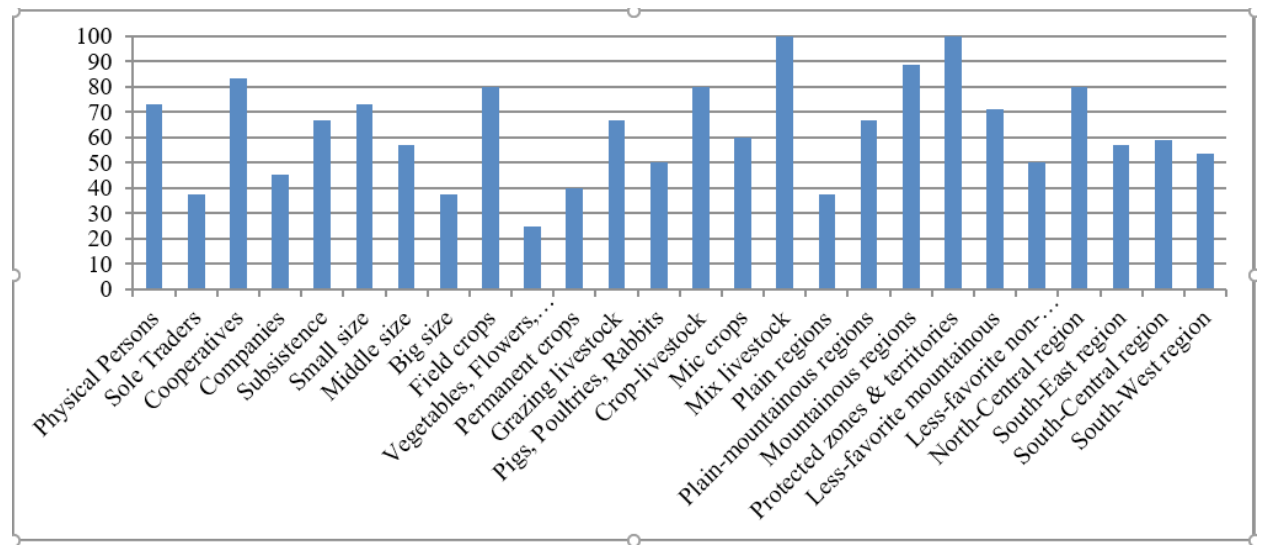

Figure 4: Negative impact of existing conflicts on agrarian resources on agrarian sustainability in Bulgaria (percent). Source: Interviews with managers of farms, 2017.

To the greatest extent conflicts over agrarian resources affect negatively the Cooperative farms $(83,33 \%)$ and holdings of Physical Persons $(73,33 \%)$. On the other hand, the adverse impact of that factor to a lesser extent is faced by the firms of various types. Agro-firms possess or use more -efficient mechanisms for prevention and/or effective overcoming of existing conflicts with other agents on agrarian resources. Despite that a good proportion of Sole Traders (37,5\%) and Companies $(44,45 \%)$ evaluate, that conflict on agrarian resources impact negatively agrarian sustainability. 
The negative impact of conflicts, related to agrarian resources, increases along with the reduction of farm size, and it is typical for holdings with Small sizes (73,33\%), semi-market holdings $(66,67 \%)$, and farms with Middle sizes (57,14\%). Furthermore, a considerable portion of Large farms $(37,5 \%)$ also indicate, that such conflicts diminish agrarian sustainability. To the greatest extent the conflicts over agrarian resources influence different aspects of agrarian sustainability in sectors Mix livestock (all farms), Field crops and Mix crop-livestock (four fifths of holdings), Grazing livestock (two thirds of farms), and Mix crops (60\% of holdings). The adverse effect of conflicts on resources is smallest in sectors Vegetables, Flowers and Mushrooms (one quarter of farms), where the amount of employed agrarian resources in individual holing and overall is also relatively small.

The negative impact of conflicts, associated with agrarian resources, on agrarian sustainability is the most pronounced in Mountainous regions $(88,89 \%)$ and in (all) farms with Lands in protected zones and territories, and to the less extent in Plain regions of the country. The latter is consequence of the fact, that in mountainous regions the amount of agrarian resources is relatively limited and all related conflicts affect severely the sustainable development in such regions. The negative impact of that factor to a greater extent is expressed in North-Central region, in comparison with studied south regions of the country.

Possibilities and costs for disputing of absolute and contractual rights through a legitimate way are important feature of the institutional environment greatly determining opportunities for sustainable development. When there is no practical possibility to enforce (protect) legitimate rights or resolve emerging disputes and conflicts between agents through legitimate way or costs for disputing rights on resources and contractual terms through a third party (court, administration, local authority, independent expertise, arbitrage, etc.) are too high, then realization of economic, social, and environmental objectives of sustainable development is difficult.

According to a big part of the interviewed managers (47,5\%) the real "possibilities and costs for disputing rights and contracts through a legitimate way" affect negatively agrarian sustainability (Figure 2). That is a consequence of the fact, that legitimate means for disputes and conflicts resolution are actually "impossible", not accessible or too expensive for using by the significant fraction of agrarian agents. For example, many surveyed agricultural producers complain from a delayed payment of purchased produce by big buyers, processors and/or food chains, or untimely provision of subsidies, compensations or assistance by the responsible state agencies. Often delayed payment by private agents or government organizations takes months, and in some cases years (e.g. compensation for damages from natural disasters), and sometimes not take place at all.

Many instances are reported, when it is too expensive or practically impossible to enforce legitimate rights on certain resources or activities through awful way, due to not working, slow or costly to use by individual agents public system of identification, enforcement, disputing and provision of rights. In all these cases, unilateral dependent from certain buyers and/or state institutions agricultural producers are harmed, without being able to enforce legitimate rights on resources and activities, or get compensation for realized losses or missed benefits. What is more, when costs (for enforcement) of private contracts are enormous then agents replace the most effective form for governing of agrarian sustainability with less efficient, but "safer" mode for safeguarding their investments and interests - restrictions of deals and relationships with market agents, personification of trade, weaker cooperation with external agents, complete (internal) integration of transactions, targeting short-term benefits and solely own (private) profit, etc.

Only for a small portion of holdings $(15 \%)$ the possibilities and costs for disputing the rights and contracts through legitimate way impact positively diverse aspects of agrarian sustainability. At the same time, according to a relatively big portion of the farms $(37,5 \%)$, that possibilities and associated costs are neutral in regards to sustainability. These figures indicates, that for the majority of Bulgarian holdings the official system for disputing the rights and contracts either "work" well, or they possess (use) other informal and more-effective mechanisms for protection of their rights and contracts - good relations, privileged and/or powerful positions, personal connections, assistance from a third party, unlawful modes, etc. Some holdings do not need at all to use the official system of conflict resolution due to the lack of interest or conflicts over resources and obligations with other parties - small amount of owned or used resources, absence or small number of contractual relations, etc.

Possibilities and costs for disputing the rights and contracts thorough legitimate way are negative factor for agrarian sustainability for two third of Physical Persons and every another one of Sole Traders, one third of Cooperatives, and just above a quarter of Companies (Figure 5). Apparently, the last types of farming enterprises possess greater possibilities for covering (often high) costs associated with the protection of private rights and contractual obligations. 
Citation: Bachev H (2018) Impact of Property Rights and Regulations on Agrarian Sustainability in Bulgaria. Arch Bus Adm Manag: ABAM-112. DOI: 10.29011/ ABAM-112. 100012

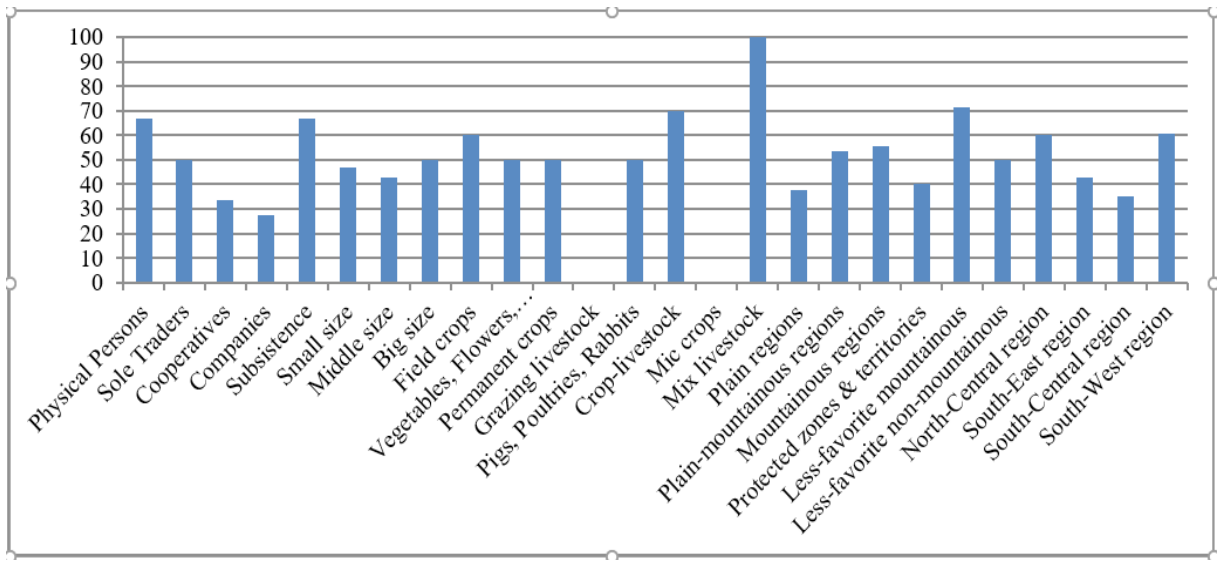

Figure 5: Negative impact of possibilities and costs for disputing rights and contracts through legitimate way on agrarian sustainability in Bulgaria (percent). Source: Interviews with managers of farms, 2017.

Among holdings with smaller sizes and the biggest farms comparatively larger number feel the adverse impact of that factor. That is due to high costs of a "unit" of contestation, lack of experience, capability, possibilities, low frequency, etc. (for the former type of farms) or significant "overall" costs for multiple disputes as a result of the scale of activity, employed resources and contractual relations with other parties (for the latter type of farms). The negative impact on agrarian sustainability of the existing possibilities and costs for disputing of rights and contracts through legitimate way is dissimilar in different agricultural subsectors. Those factors adversely affect all or predominant part of holdings with Mix livestock (100\%), Mix crop-livestock (70\%), and Field crops $(60 \%)$. Among farms specialized in Permanent crops, Pigs, Poultries and Rabbits, and Vegetables, Flowers, and Mushrooms, the negative impacts is reported by each another one. For all of the managers of holdings, specialized in Grazing livestock and Mix corps, possibilities and costs of disputing the rights and contracts through legitimate way are positive or neutral factor for agrarian sustainability.

In various ecosystems to the greatest extent are exposed of the negative impact of possibilities and costs for disputing the rights and contracts through legitimate way the farms in Lessfavored mountainous regions $(71,43 \%)$, Mountainous regions generally $(55,56 \%)$ and Plain-mountainous regions $(53,33 \%)$, On the other hand, farms located in Plain regions, and those with Lands in protected zones and territories, suffer to a lesser extent by the adverse effect of that factor. There is a great regional differentiation in the effects of the system and costs for disputing the rights and contracts through lawful way. To the biggest extent by the inefficiency of the existing system suffer holdings located in South-West and North-Central region of the country $(60 \%$ of all), while farms in South-Central region are affected to the least extent $(35,29 \%)$. Existing regional differentiation of the impact of that factor is determined by the different efficiency of the formal system of disputing of rights in each region, specific structure (and efficiency) of informal institutional environment and modes of governance, and unlike needs, challenges, contractual structure, accumulated experience, and internal capability of farms in each region and ecosystem.

Provision of rights to use agrarian resources (farmlands, meadows and pastures, fishponds, water basins, etc.) is an important factor for their sustainable management (exploitation) as well as for sustainable development of agriculture in certain regions (mountainous, less-favored, with limited resources, inhabited or in a process of depopulation, etc.) and some major subsectors (livestock, collection of wild plants and animal species, etc.). A significant part of the surveyed holdings (37,5\%) report, that the "free access to public lands" is an essential positive factor for agrarian sustainability, simultaneously for the economic as well as social and environmental aspects (Figure 2). At the same time, none of the managers assesses that such an access impact negatively the agrarian sustainability.

Despite that, many small producers in mountainous and other regions complain, that public lands not always are fairly distributed. Many instances are reported for allocation of public (state, municipal) pastures and meadows in large sizes to individuals and groups "with connections", for which lands huge public subsidies are received. Such modes decrease social efficiency (sustainability), although they may not necessarily change (even could increase) economic and/or environmental sustainability of land use in the region. What is more, in many residential areas there are no (sufficient) municipal pastures and that creates series problems for sustainable development of many small-scale livestock breeders. On the other hand, in certain regions the land and other resources with "free access" are not utilized 
sustainably due to overuse (more that allowed number of livestock on a pasture, uncontrolled collection of wild plants, snails, etc.) or underuse (lack of care for public resources due to the "absence" of owners).

To the greatest degree the favorable impact of such institutional organization ("free" rather than restricted or no access to public lands) on agrarian sustainability is reported by the Physical Persons and holdings Predominately for subsistence (two third of the total number), Companies (36,36\%) and Small size farms (40\%), all farms specialized in Grazing livestock and Mix livestock, as well the majority of the Mix crop-livestock holdings $(80 \%)$ (Figure 6). The positive impact of that factor is confirmed by the farms, located in Mountainous regions (77,78\%), in two third of holdings in Less-favored non-mountainous regions, and most of the surveyed farms in the South-East region $(57,14 \%)$. The latter is subsequence of the fact, that mostly holdings with small size, growing grazing livestock, located in the mountainous regions of the country, to the greatest extent take advantage of such good opportunity. In these regions private agricultural lands are limited and there are large pastures and meadows, which are widely provided for use to local farmers. In some cases bigger livestock holdings, which are with juridical status of companies also use large municipal and state pastures and meadows. Therefore, all these produce appreciate the positive effect of the free access to public lands on agrarian sustainability.

Well formulated and controlled social rights and obligations are important element of the institutional environment, which is to improve the social aspect and the overall level of agrarian sustainability. Well defined and effectively enforced social rights of individual agents (hired labor, residents and visitors of rural areas, final consumers, etc.) facilitate relationships, secure a public protection of "weak" parties, and lead to improvement of social and overall sustainability in agriculture. According to one fifth of the interviewed farms managers "defined social rights and obligations" at the current stage of development have positive impact on agrarian sustainability, and particularly on its social aspect (Figure 2). The favorable impact is pointed out by the majority of Cooperative farms, in which social goals are principally an essential priority for the overall activity. One of the interviewed presidents of cooperatives underlines, that social responsibilities for providing employment for members are important, and therefore the coop members accept lower labor productivity in comparison to other structures. The positive impact on agrarian sustainability is also determined by other big employers (Sole Traders, Companies), which believe that social rights of workers are to be respected, and that secured workers are also economically more productive, and ecologically more efficient.

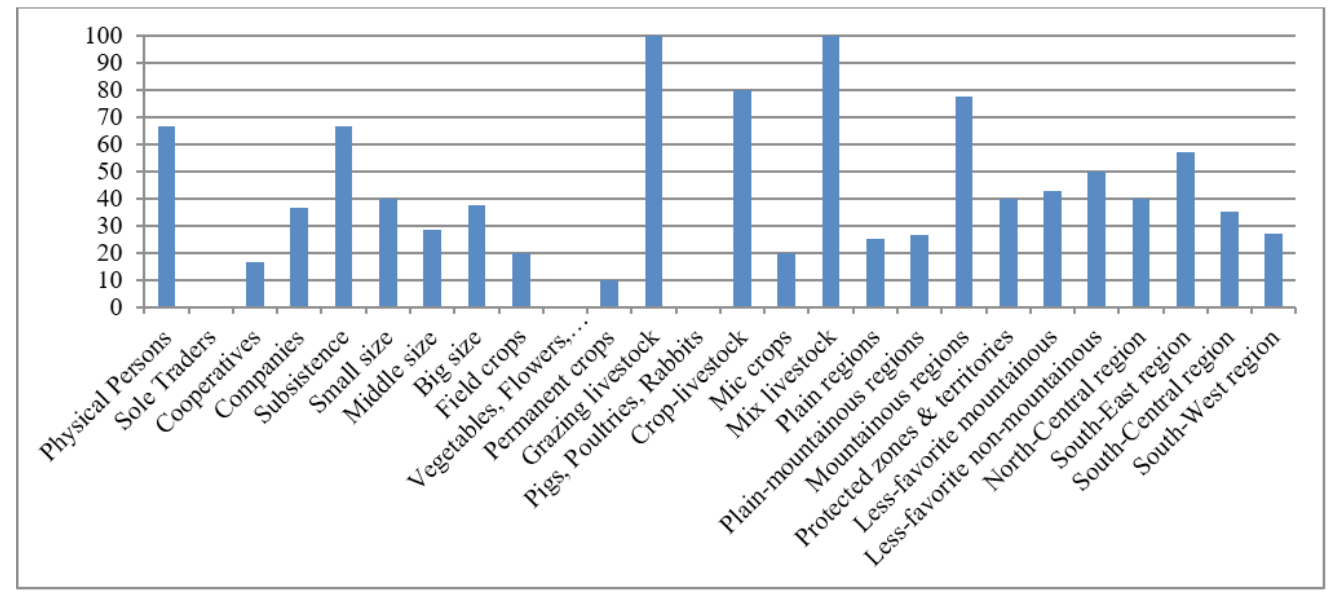

Figure 6: Positive impact of free access to public lands on agrarian sustainability in Bulgaria (percent). Source: Interviews with managers of farms, 2017.

However, for the majority of the surveyed farms $(67,5 \%)$ formally defined by the institutional environment social rights and obligations do not have any impact on agrarian sustainability or any of its individual aspects (including social one). That is a consequence of the fact, that many formal norms and standards, related to social rights, labor conditions and payment, etc. are not well respected or controlled in agriculture.
Fora good fraction of the farms $(12,5 \%)$ regulatory determined social rights and obligations have a negative impact on agrarian sustainability. Principally, bigger holdings and major employers are forced to comply to a greater extent with official norms for contracting, working conditions, wage payments, insurance, social security, etc. These farms are subject of considerable public subsidizing and along with that to a stricter control and sanctions 


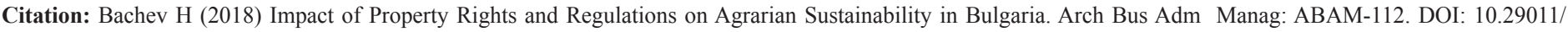
ABAM-112. 100012

by the state agencies for noncompliance with variety of (quality, social, environmental, etc.) standards. For some managers "new" social obligations, arising from the modernization of legislation, are associated with additional costs and diminishing economic efficiency, and together with that of overall sustainability of the sector. A large interviewed employer of seasonal labor pointed out as example the high costs for labor and social security payment (reaching up to a third of the total firm's costs), and for preparing temporary contracts, and for constant issuing of orders for unpaid leave of absence due to unregularly appearance to work, and for termination of contracts, and for penalties, etc. At the same time it is underlined, that competitors with a smaller size in the "shadow economy" attract workers with higher wages.

On the other hand however, the greatest portion of the interviewed managers $(82,5 \%)$ believe, that "efficiency of controlling social rights and obligations" is a neutral factor for agrarian sustainability and its individual aspects (Figure 2). That is due to the fact that implementation and enforcement of social rights and obligations in the sector (similarly to other sectors in the country) is not at a good level and have no real impact on sustainability and its social aspect. Simultaneously, a good portion of holdings $(12,5 \%)$ assess as positive the impact of effective control on social rights and obligations. That is a consequence of that fact, that a stricter control improves significantly the status-quo and lead to implementation of otherwise "good" social standards and norms, introduced during pre- and post-accession to European Union. At the same time, for a relatively little part of the farms (5\%), "improved" control on strict implementation of social rights and obligations is undesirable, because it considerably increase costs of production and affect negatively the overall sustainability of holdings activities.

Well-defined and enforced environmental rights and obligations are a major element of the institutional structure at the contemporary stage, and important factors for sustainable exploitation and conservation of natural resources. They are particularly crucial in agrarian production, which is a major polluter and user of natural environment, as well as one of the key factors for preservation, recovery and amelioration of natural resources. In pre-accession period and after the integration of the country to the European Union a significant modernization of environmental rights have taken place, as eco-standards have been harmonized with superior European levels, new rights and rules introduced for use and conservation of lands, waters, air, ecosystem services, etc., protection and improvement of biodiversity and landscape, compliance with principles of animal welfare, etc.

According to the significant part of the interviewed farm managers $(37,5 \%)$ "defined eco-rights and obligations" affect positively agrarian sustainability, particularly its environmental aspect, and eventually contribute to enhancing social and economic dimensions of sustainability as well. The favorable impact of that factor is assessed equally by holdings with different juridical type, specialization, sizes, geographical and ecological location. A big number of agricultural producers receive public subsidies, which require complying with modern eco-standards and norms. Besides, there are special measures for assisting agro-ecology and organic production imposing even higher environmental standards. There are also introduced numerous norms and standards for protection and exploitation of natural resources as a whole or in certain regions (NATURA, less-favored, protected zones and reserves, etc.), which are obligatory for agrarian resources owners, agricultural producers and non-agrarian agents (industry, residents, visitors, etc.).

Only a tiny section of surveyed farms (5\%) indicate that the structure of regulated eco-rights and obligations is a negative factor for agrarian sustainability. The latter is consequence of the fact that adaptation of holdings to requirements of new environmental rules in the sector is associated with additional costs or considerable lost benefits. At the same time, the majority of interviewed managers $(57,5 \%)$ believe, that defined eco-rights and obligations are not important for agrarian sustainability, including its environmental aspect. Very often agricultural producers are not well familiar with or implement new eco rules and norms due to the lack of means, capability for adaptation or weak (practically impossible, too expensive, politically unacceptable) control by the state bodies. Subsequently most agricultural producers do not put any importance on the structure of eco-rights and eco-obligations in the governance of agrarian sustainability.

In other instances provided rights for profiting from ecoactivities and products do not allow obtaining any market and contractual bonus. According to some of surveyed holdings, which are certified for organic production, they mostly sell their output at normal market prices without receiving needed bonus for organic produce. That is further reinforced due to the fact that internal demand for organic produce in the country is not big, markets for agrarian organic products are in the process of development, and/ or many small producers have no access to such markets.

Moreover, three quarters of surveyed farms do not think, that the "efficiency of the control of eco-rights and obligations" is of significant importance for agrarian sustainability, and for environmental aspect in particular (Figure 2). The reason for the latter is that permanent control on eco-standards in a geographically extensive and multifaceted sector like agriculture is relatively weak (or practically impossible), violations are easily hidden, often disputed or difficult to prove (through expertise, court, etc.), while sanctions for noncompliance are insufficient to induce mass pro-environment behavior. On the other hand however, every fifth holdings believes that improved efficiency of the control on eco rights and obligations in the past years affect favorably agrarian 


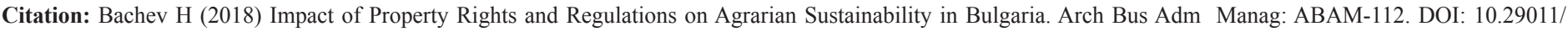
ABAM-112. 100012

sustainability and its environmental dimensions. These are mostly larger producers, which understand well and try to comply with mandatory standards for quality, ecology, protection of nature and biodiversity, etc. These holdings strive to preserve (and improve) quality of utilized natural resources, since to a greater extent are controlled by the state bodies, and greatly suffer from detected violation and sanctions (fines, ceasing production, restoration costs, etc.). Some producers also think that "production" pressure of the sector on environment is not strong due to low application of fertilizers, crop protection chemicals, intensification of activity, etc.

Relatively few farms (5\%) indicate, that control efficiency on eco-rights and obligations affect negatively agrarian sustainability. Those are producers which are either unconvinced (aware) with the meaning of effective eco management, or disinterested in the latter (due to advance age, part time involvement of farming, practicing a short-term lease of others resources, negative impacts on third parties, etc.), or have no financial, expert etc. capabilities to carry necessary eco-activities in a needed scale and terms. For that type of producers the improved public control is an "obstacle" for sustainable development of their holdings, since it is associated with additional costs for eco-actions, payments of penalties for violations, bribes to controlling authorities, etc. Many examples are presented for not provided accurate information about the real (eco)state in order to trade on markets and/or participate in public programs, professional and other organizations, as shortage of efficient "external" (quality, integral crop protection, pollution, waste management, etc.) control favor that. For instance, in order to take part in the selection control, an interviewed cooperative provides inaccurate information for the number of livestock, to prove unfeasible (but required) normative milk yield per cow head.

Creation of an environment for effective market competition in the country and its individual regions is an important factor for efficient resources allocation and utilization and for governing sustainable development of the sector. A big portion of interviewed holdings $(40 \%)$ report that "existing market competition in the country" impact positively agrarian sustainability and its aspects (Figure 2). Bulgaria is a small country and many bigger farms compete successfully with local and international producers in a nationwide scale. However, for the majority of interviewed managers $(42,5 \%)$ the type and character of market competition in the country is a negative factor for agrarian sustainability. Many farmers believe that there are not favorable conditions for loyal competition with foreign goods and between domestic producers. As reasons for the latter are following: policies for trade liberalization (including countries outside of the European Union), bad regulations and/or control for illegal import, domination of large buyers (food chains, processors, exporters, middlemen, etc.), wide informal (shadow) sector in the country, unequal public support to different subsectors of agriculture and type of producers, etc. An interviewed big livestock farmers indicates, that multiple bankruptcies in recent years as a result of the "low milk price" are a serious problem, still waiting solution. Another farmer in integrated grape and wine production lost his winery due to a failure to pay high bank interests. According to that manager it is necessary to establish a guarantee (supporting) national fund in order to prevent failures of structures with a high productivity but financial difficulties.

Many surveyed farmers also report, that the severe market competition leads to compromising social and environmental aspects of agrarian sustainability in order to maintain economic vitality. Examples are also given for missing or undeveloped markets for certain products in agriculture such as Lucerne, silage, manure, lack of short or long term agrarian credit, etc. In the latter cases, producers look for private ways for dealing with the issues - own production, contraction of activity, free provision, barter or combine exchanges, illegal waste disposal, contracts for chemicals etc. supply interlinked with crediting ("portion payment"), and so forth. Another reason for that problem in the country is that still there are not developed more complex and (often) more efficient market forms as alternative of competition with current prices such as future deals, forecasting and waiting for "high" prices, longterm contracts, vertical integration, etc. That is a consequence of the insufficient experience, information, superior costs (for of harvest storing, keeping, etc., contracting), uncertainty and risk for holdings, etc.

For a relatively small portion of the farms $(17,5 \%)$ market competition in the country is a neutral factor for agrarian sustainability. Those are mainly smaller size producers, semimarket holdings or farms with unique produce and guaranteed marketing (due to freshness, superior taste, preferred local products and varieties, etc.). That type of producers has no serious competition in local or regional scale and/or competes with big players at national or international scale.

The negative impact of market competition in the country on agrarian sustainability is faced differently by farms of various juridical type, sizes, production specialization, geographical and ecological location. To the greatest extent the adverse effect on agrarian sustainability is felt by Physical Persons (53,33\%), holdings with Small size (60\%), producers specialized in Vegetables, Flowers, and Mushrooms (75\%), Grazing livestock (66,67\%), Permanent crops (60\%), and Pigs, Poultries and Rabbits $(50 \%)$ (Figure 7). The latter categories of holdings and agricultural subsectors mostly suffer from the intensification of competition in the country in the past several years. 
Citation: Bachev H (2018) Impact of Property Rights and Regulations on Agrarian Sustainability in Bulgaria. Arch Bus Adm Manag: ABAM-112. DOI: 10.29011/ ABAM-112. 100012

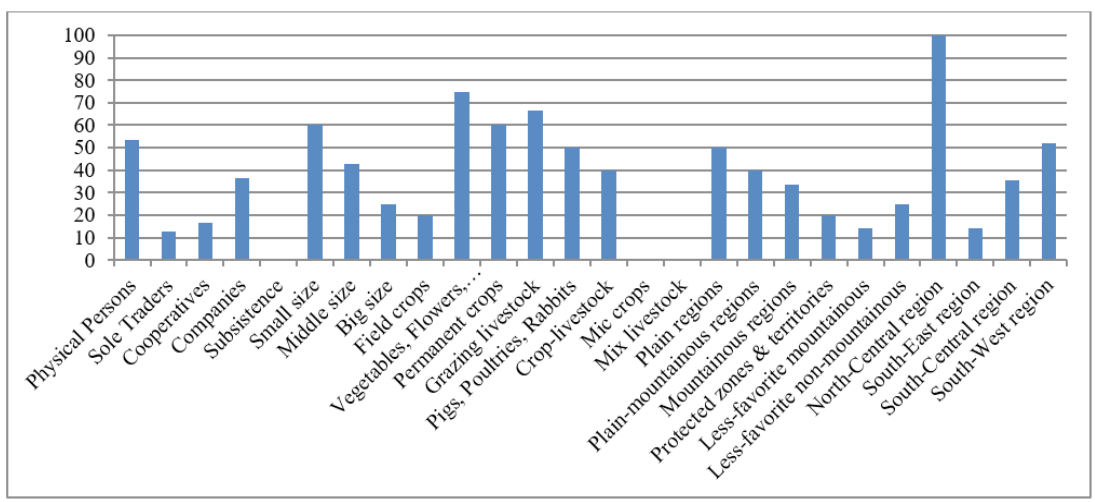

Figure 7: Negative impact of existing market competition in the country on agrarian sustainability in Bulgaria (percent). Source: Interviews with managers of farms, 2017.

Existing nationwide market competition is a negative factor in regards to agrarian sustainability for every another farms situated in Plain regions of the country, for all holdings in North-Central region, and more than a half of the farms in South-Central region. The adverse effect to the least degree impact Sole Traders (12,5\%) and Cooperatives (16,67\%), farms with Big sizes (25\%), holdings specialized in Field crops (20\%), and located in Less-favored mountainous $(14,29 \%)$ and non-mountainous $(25 \%)$ regions, as well as with Lands in protected zones and territories (20\%). All these type of farms, production subsectors, and ecological regions are with superior comparative advantages for exploration of economies of scale and scope in production and marketing, with good competitive and negotiating positions, established reputation and effective marketing channels. Moreover, these holdings, productions and regions also enjoy the biggest public support subsidies for areas of utilized lands, agroecology, less-favored regions, etc.

For the majority of surveyed agricultural producers $(60 \%)$ "existing market competition in the region" is a neutral factor in relation to agrarian sustainability and its aspects. The little importance of the local competition is caused by the fact that many of producers work (and compete) for national and international markets and/or supply giant commercial chains and processors. Competition at local level is between limited numbers of small producers for restricted number of local buyers, and here relations are "governed" by personal, rather than market connections high trust, elaborated clientalisation, and high frequency of deals between same partners, etc.

Simultaneously, for a good proportion of the interviewed managers $(22,5 \%)$, market competition in the region is a negative factor for agrarian sustainability, and particularly its social and environmental dimensions. The latter is mostly typical in the regions with intensive production, high population density, and for smaller size commercial holdings. What is more, many of interviewed managers indicate the lack of sufficient qualified and low skilled workers in the sector as one of the main factors, obstructing development at the current time. The latter demonstrates that local markets do not work well and bring an increase in the prices and "satisfaction" of existing demand for hired labor. Subsequently farm size is not expended to the effective scale, or important agro-technical and other activities implement in an effective scale, or more expensive mode of governance applied (as a permanent labor contract, purchase of external services, leasing out of "idle" resources, etc. instead of using a contract for seasonal employment). Many managers also complain from the shortage of financing in agriculture, which is indicative that loan markets do not work well at local and national level (unattractiveness, high risk, long pay back periods, etc. in the sector). Many examples are also given for farmers selling output and /or supplying from agents in other (often remote) regions, because local suppliers and buyers are not reliable (delayed implementation or default of negotiated terms).

On the other hand, a good portion of surveyed farms $(17,5 \%)$ indicate the positive impact of market competition in the region on agrarian sustainability. A well working local market provides opportunity for numerous smaller producers in the region to realize comparative advantages in relation to producers (products) of other regions of the country and/or import - lower prices, higher quality, freshness, origin authenticity, rapid and quality supplies, produce marketing in a "package with service" (farm visit, protection of nature, personal consultation, etc.). Superior competitiveness allows not only to maintain the economic vitality of local farms, but also to improve their social and environmental functions.

Liberalization and costs, associated with international trade, are important factors for stimulation of local producers and realization of their competitive advantages in larger international scales. The majority of surveyed holdings $(57,5 \%)$ do not directly take part in export or compete immediately with imported goods, 
and for them "possibilities and costs for import and export" are neutral factor for agrarian sustainability and its aspects (Figure 2). The majority of interviewed managers $(27,5 \%)$ evaluate at positive the existing possibilities and costs for import and export on agrarian sustainability at current stage. Those are mostly larger producers in export oriented or related agricultural subsectors, for which possibilities for effective participation in international trade additionally improve some or all aspects of agrarian sustainability in the country. At the same time however, for $15 \%$ of holdings, the good opportunities and low costs for import and export ("globalization") are negative factor diminishing competitiveness, destroying national production and producers, and having not only socio-economic but also environmental consequences (devastation of family holdings, inferior lands fertilization and cultivation, lack of irrigation, practicing monoculture in large scales, unproductive utilization and/or abandoning of fertile lands, lost traditional varieties, productions, and biodiversity, etc.).

Legislative and regulatory arrangements are important element of the institutional environment, which are to regulate (govern) the maintenance or achievement of agrarian sustainability and all of its aspects. According to the majority of interviewed managers $(47,5 \%)$ existing in the country "legislative and regulatory arrangements" do not any effect on agrarian sustainability or its aspects (Figure 2). The latter means that either the system of laws and formal regulations does not aim at improving agrarian sustainability, or the extent of implementation and enforcement of the system of laws and rules contribute to achievement of goals of sustainable agrarian development. For example, many interviewed managers confess that they apply for different type of subsidies (for products, ecology, organic agriculture, etc.) only to get public support, and after that they destroy subsidized crops. Obviously, such kind of subsidies (public "assistance") has no particular benefit for agrarian sustainability and program objectives (besides creating temporary employment).

A good fraction of the farms $(32,5 \%)$ assess as negative the impact of legislative and regulatory settings in the country on agrarian sustainability. Numerous farmers complain that the multiple regulations of the Ministry of Agriculture and Food are difficult to study, not published on time, with a very short period for examination, preparation and application for support or complying with regulations, while sanctions for violation are great. The latter means that existing laws and regulations at the present time of development in the country do not stimulate or regulate well activity of the main agents in the sector (farm managers, owners of agrarian resources, agrarian bureaucracy, users of agricultural produce and services). In some instance, they even obstruct realization of socio-economic and environmental aspects of agrarian sustainability. An interviewed large producer gives a good example demonstrating how difficult and costly is to register a big size combine purchases in Yambol (South-East Bulgaria). Combine inspection and registration have to be done in Sofia (300 $\mathrm{km}$ away in West Bulgaria), and numerous (for each administrative region) special permissions are required for movement of the combine through all 7 regions from Yambol to Sofia. In order to deal with that challenge unlawful driving of the combine in the country is undertaken (with paying fines and/or bribes to police). Also many examples are shown for delayed payments of subsidies, compensation, etc. by the state agencies, creating enormous difficulties for producers of different type. Merely for each fifth of the interviewed managers, the contemporary legislative and regulatory arrangements contributes (impact positively) to accomplishing agrarian sustainability.

There is a great differentiation in the negative impact of the legislative and regulatory settings on the behavior for sustainable agriculture of producers of different juridical type, sizes, product specialization, geographical and ecological location (Figure 8). To the greatest extent the adverse impact of the legislative and regulatory framework affect Physical Persons (40\%) and Companies $(45,45 \%)$, holdings with Small size $(46,67 \%)$, and those specialized in Vegetables, Flowers, and Mushrooms (75\%), Grazing livestock (66,67\%), Mix crop-livestock (50\%), as well as farms located in the Less-favored non-mountainous regions $(50 \%)$, and North-Central and South-Central regions of the country (accordingly $40 \%$ and $46,06 \%$ ). 
Citation: Bachev H (2018) Impact of Property Rights and Regulations on Agrarian Sustainability in Bulgaria. Arch Bus Adm Manag: ABAM-112. DOI: 10.29011/ ABAM-112. 100012

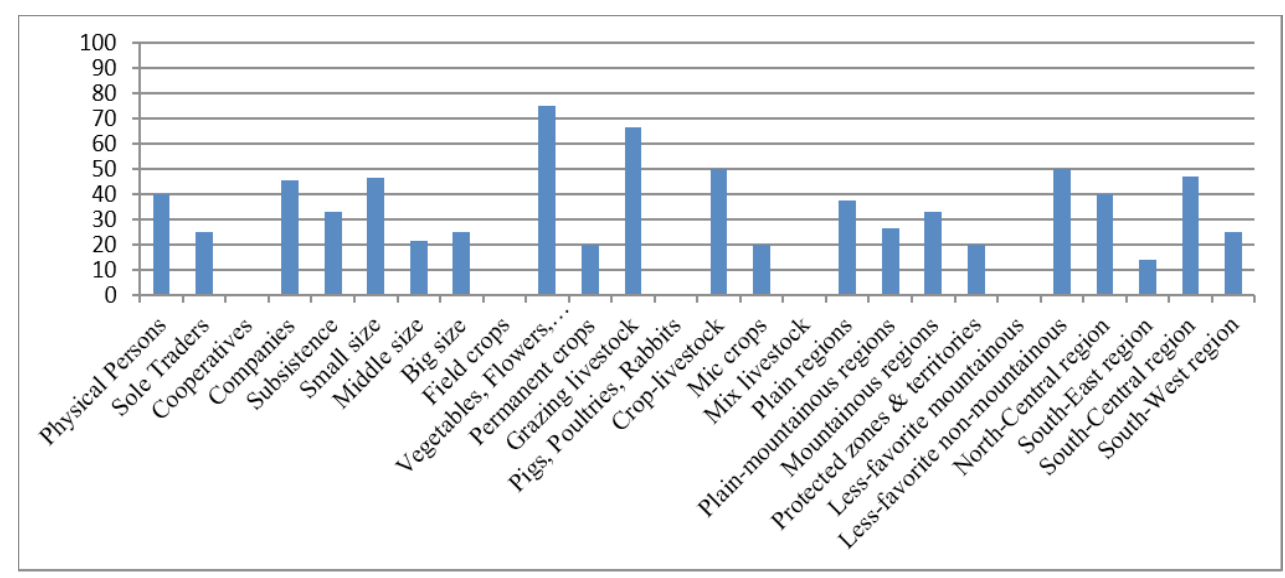

Figure 8: Negative impact of existing legislative and regulatory arrangements on agrarian sustainability in Bulgaria (percent). Source: Interviews with managers of farms, 2017.

On the other hand, legislative and regulatory settings do not affect adversely agrarian sustainability in Cooperatives and holdings, specialized in Field crops, Pigs, Poultries and Rabbits, Mix livestock, and farms in Less-favored mountainous regions. The negative impact of the legislative and regulatory arrangement is lesser for Sole Traders (25\%), holdings with Middle (21,43\%) and Big (25\%) sizes, and in subsectors of Permanent crops and Mix crops (each 20\%), located in Plain-mountainous regions $(26,67 \%)$, and with Lands in protected zones and territories (20\%). To the least extent the legislative and regulatory framework affects agrarian sustainability of farms in South-East $(14,29 \%)$ and SouthWest (25\%) regions of the country.

Official standards for product quality, working conditions, environment protection, etc. greatly (could) facilitate activity and relations of various agents, assist increasing efficiency, and sustainable development. According to more than a half of interviewed farmers $(52,5 \%)$, existing in the country system of "formal standards for products, labor, etc." has no impact on agrarian sustainability and its socio-economic and environmental aspects. That is a consequence of the fact, that dominating system of formal standards is not directed toward realization of diverse goals of agrarian sustainability in the greatest part of agricultural producers, due to a bad design, mismatch with practical needs and/ or inferior practical implementation.

At the same time however, $30 \%$ of surveyed farms believe that official standards for products, labor, etc. support sustainable development and are a positive factor for achieving agrarian sustainability and its main aspects. Apparently, introduction and control of modern standards of European Union for products quality and safety, conditions and assurance of labor, natural resources protection, cross-compliance, etc. also contribute to improvement of agrarian sustainability in the country. The latter however, concerns mostly larger producers and major market players, having greater capability, strong interests and financial means to introduce new standards and meet market and institutional requirements. That also concerns the best part of holdings receiving public subsidies and participating in various support programs, since they are a subject of constant and stricter control by different state bodies.

For a good portion of holdings (17.50\%) adaptation to novel quality, environmental, labor, etc. standards is too expensive, technically not feasible, undesirable or unnecessary, and leads to negative consequences in regards to agrarian sustainability or some of its aspects. Principally, those are smaller-size holdings, with a lower capability (expertise, financial potential) for adaptation, in less developed regions of the country, as well as owned by advance age entrepreneurs. That type of farms also suffer greatly from enhanced control for precise compliance with modern standards from the state authority, due to the high costs for adaptation and complicated bureaucratic procedures, impossibility or big losses from paying penalties, bribes, etc.

The actual implementation of existing laws, standards, rules, etc. is an important component of the institutional environment and factor for sustainable development. In Bulgaria the entire legislation was "harmonized" with that of European Union and high standards for quality, safety, environment protection, animal welfare, etc. introduced in the pre-accession period. Despite that, a big part of otherwise good laws and regulations does not work well due to the bad implementation by the state and private agents, insufficient control and lack of efficient mechanisms for stimulation and/or punishment. It is not by accident that a majority of the interviewed farm managers $(45 \%)$ report that the "real implementation of laws, standards, etc." in Bulgaria is a negative factor for agrarian sustainability (Figure 2). The biggest fraction of the farmers believe that there is not supremacy of law and/or laws and rules are implemented equally to all in the sector and/or equally well in all regions of the country. There are also some managers, 
Citation: Bachev H (2018) Impact of Property Rights and Regulations on Agrarian Sustainability in Bulgaria. Arch Bus Adm Manag: ABAM-112. DOI: 10.29011/ ABAM-112. 100012

according to whom "good" enforcement of certain laws and rules id not associated with real improvement of individual aspects of agrarian sustainability, due to inferior (not corresponding to the needs, costly for agents, cumbersome, etc.) regulatory system.

An important part of interviewed managers $(37,5 \%)$ assess as neutral the impact of the actual implementation of laws, standards, etc. on agrarian sustainability. In many cases, existing on paper "good" laws and standards practically "are not implemented" or incompletely applied. That consequently leads to nonfulfillment of expected results for amelioration of diverse aspects of agrarian sustainability. The smallest portion of surveyed managers $(17,5 \%)$ suggests that real implementation of laws, standards, etc. is effective, and that contribute to improvement of socio-economic and environmental aspects of agrarian sustainability. Those are agricultural producers, subsectors and regions, where formal laws and rules are applied and controlled comparatively well and that is associated with an actual enhancement of agrarian sustainability. That share of farms give also approximate insight for (insignificant) extent of agricultural holdings in the country, in which official rules, standards, norms, etc. are implemented and controlled well.

To the greatest extent the negative impact of the (low) "efficiency" of the system of actual application of laws, standards, etc. is faced by Companies (54,55\%), Sole Traders (50\%), Physical Persons $(46,67 \%)$, holdings with Small $(46,67 \%)$ and Big $(62,5)$ sizes, producers specialized in Vegetables, Flowers, and Mushrooms (100\%), Mix livestock (100\%) and Mix crop-livestock (70\%) (Figure $8 b)$. On the other hand, Cooperatives $(16,67 \%)$, farms with Middle size (21,43\%), holdings specialized in Grazing livestock (0\%), Field crops and Mix crops (by 20\%), and Permanent crops, to a lesser degree are affected by the adverse impact of that factor. Similarly, while only a little portion of farms in Plain-mountainous regions $(26,67 \%)$ and in South-East region of the country (14,29\%) report the negative impact of agrarian sustainability of the extent of real implementation of laws, standards, etc., a comparatively greater portion of agricultural producers in Plain $(56,25 \%)$ and Mountainous $(55,56 \%)$ regions, and in South-West region of the country $(66,07 \%)$ are affected by the adverse consequences of that imperfect institutional organization.

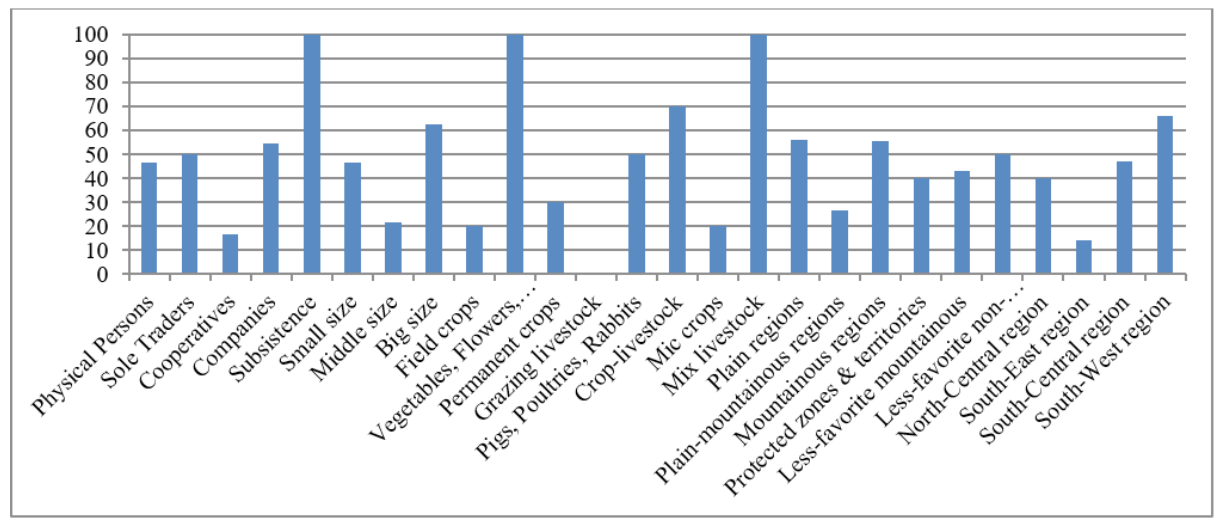

Figure 8 (b): Negative impact of the extent of real implementation of laws, standards, etc. on agrarian sustainability in Bulgaria (percent). Source: Interviews with managers of farms, 2017.

Presence, type and amount of public sanctions for violating laws, rules, norms, etc. are important factor for effective operation of the institutional environment and governing activities of various agents (resources owners. Producers, consumers, government administration, etc.). The biggest part of interviewed managers $(45 \%)$ do not think that "existing public sanctions (fines, punishments) for violation" affect in any way activities and actions of agents for maintaining and/or increasing agrarian sustainability and its aspects (Figure 2). That is a consequence of the fact that existing system of sanctions does not provoke adequate behavior for amelioration of agrarian sustainability due to insufficient amount (fines, punishments, etc.) or inefficient organization (weak control, monitoring, lack of correlation between sanctions and outcome of activity, slow procedures, etc.). At the same time, only a tiny portion of holdings $(17,5 \%)$ suggest that the system of public sanctions for violation "work well" and lead to positive results in regards to elevation of agrarian sustainability. A big proportion of farm managers $(37,5 \%)$ evaluate as negative the impact of the character and the size of public sanctions for violation on agrarian sustainability and its different aspects. That is a result of the fact that superior and adequate sanctions are associated with increasing costs for prevention of likely violations and/or payments for actual violations, without however being always connected with any or proportionate improvement of agrarian sustainability or its specific aspects.

To the greatest extent the negative impact of the public sanctions for violation are faced by the Physical Persons (40\%) and Companies $(45,45 \%)$, while among Sole Traders and Cooperatives 
affects only a quarter and a third of them accordingly (Figure 9). The latter kind of farms either have less and unimportant violations (less frequent and smaller sanctions) or the sanctions payments to a lesser extent affect the overall outcome of their activity (a tiny share of sanctions in total costs, high return on costs for sanction payments comparing to the benefits of violations, etc.)

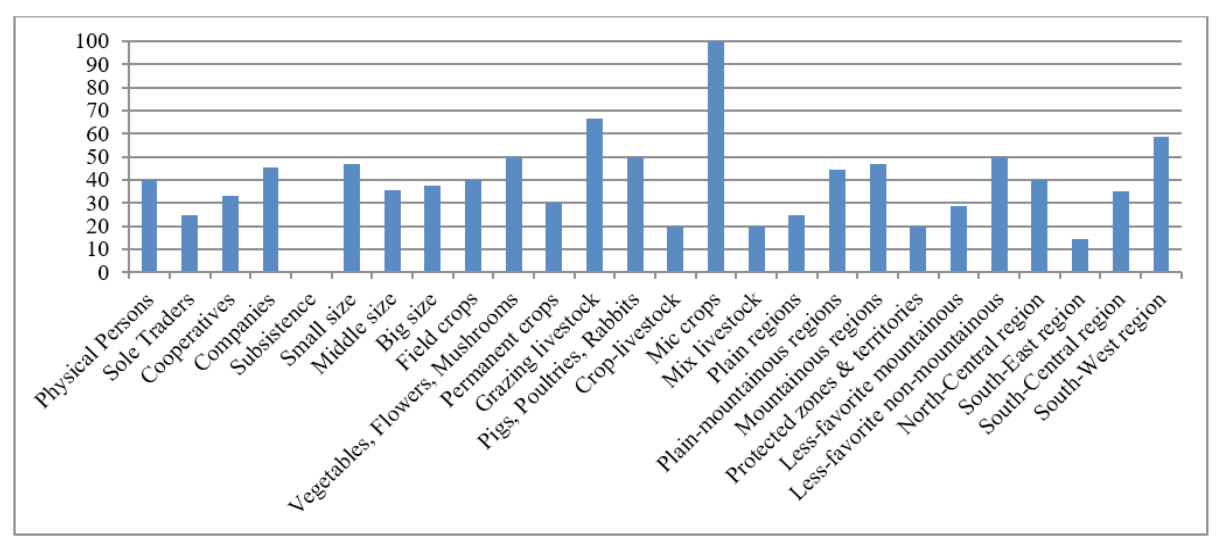

Figure 9: Negative impact of the existing public sanctions (fines, punishments) for violation on agrarian sustainability in Bulgaria (percent). Source: Interviews with managers of farms, 2017.

The adverse effect of the public sanctions for violation is greater for Smaller size $(46,67 \%)$ and farms specialized in Grazing livestock (two third of them), Mix crops (100\%), Vegetables, Flowers, and Mushrooms, as well as Pigs, Poultries, and Rabbits (correspondingly for every another one). On the other hand, farms with Mix livestock and Mix crop-livestock to a lesser extent are impacted by the system of public sanctions for violation (every fifth one). The latter either make less violations (a high compliance with public norms and standards), or their violations are more difficult to detect and effectively punished, or implemented sanctions are not proportional to received benefits from breaking rules. Depending on the ecosystems, farms located in Mountainous (46,67\%) and Plain-mountainous $(44,44 \%)$ regions as well as in Less-favored non-mountainous regions $(50 \%)$ most greatly indicate the negative effect of the public sanctions for violation. Similarly, most farms located in South-West region of the country $(58,92 \%)$ report the negative impact on agrarian sustainability of public sanctions for violation, while in South-East region of the country they are least numerous $(14,29 \%)$.

"Costs for implementation of formal and informal norms, standards, etc." are costs of the farms for adaptation to requirements of socio-economic, institutional and market environment. Along with traditional ("production") costs, they determine to a great extent the efficiency of farming activity, as their high level could impede sustainable agrarian development. According the majority of interviewed managers $(62,5 \%)$ the level of such costs have no effect on agrarian sustainability or certain aspects (Figure 2). Therefore, costs for adaptation to regulatory requirements are not important for maintaining or increasing agrarian sustainability, or the actual agrarian sustainability level does not depends on effective amount of such costs. Simultaneously merely $5 \%$ of all holdings believe that the real costs for implementation of formal and informal norms, standards, etc. have a positive impact on agrarian sustainability or some of its aspects.

At the same time however, for a relatively good portion of farms $(32,5 \%)$ growing amount of costs for adaptation to constantly evolving formal requirements of institutional and market environment as well as existing informal rules are negative factor for agrarian sustainability. It is well known that farms have high additional costs for complying with novel standards for quality, safety, ecology, etc. of the European Union, with voluntary or compulsory "codes of behavior" of various professional organizations, purchasing industries, commercial chains, consumer associations, etc. Studying out and training in/and implementation of multiple laws, norms, etc. in agrarian sphere is also associated with enormous costs for individual producers. Furthermore, agricultural producers have significant costs for "complying" with informal rules - informal standards of buyers, bribe payments, doing "favors", giving "presents" to controlling and protecting bodies and persons, etc.

The greatest adverse effect on agrarian sustainability have the amount and character of costs for implementation of formal and informal norms, standards, etc. for the managers of firms of different type - Sole Traders (37,5\%) and Companies (26,36\%) (Figure 10). On the other hand, to least extent the negative impact of that type of costs is felt by the Cooperative farms - sole 16,67\% of them. 
Citation: Bachev H (2018) Impact of Property Rights and Regulations on Agrarian Sustainability in Bulgaria. Arch Bus Adm Manag: ABAM-112. DOI: 10.29011/ ABAM-112. 100012

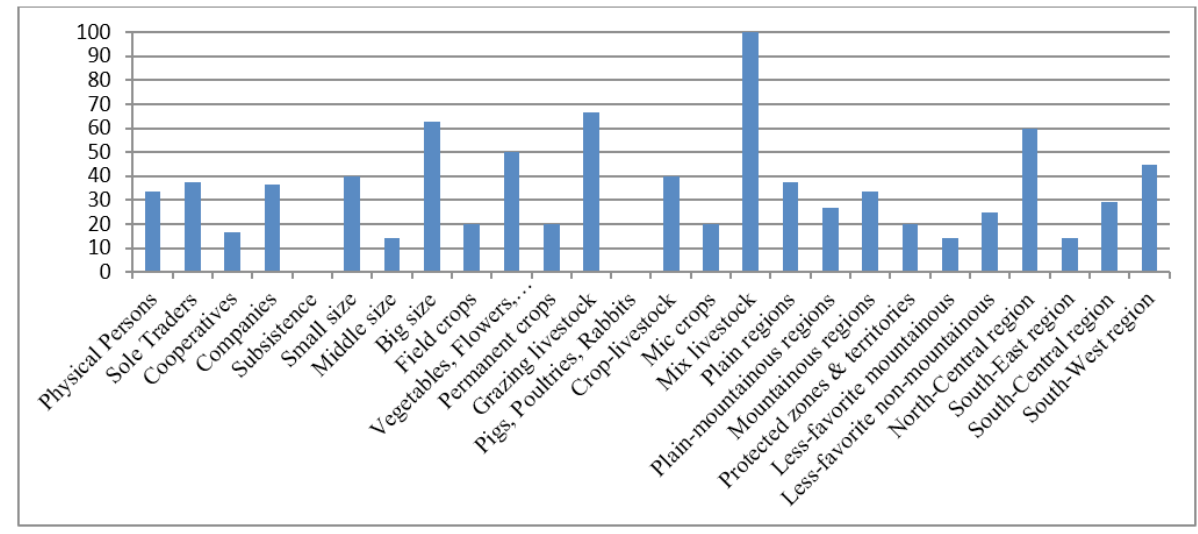

Figure 10: Negative impact of the costs for implementation of formal and informal norms, standards etc. on agrarian sustainability in Bulgaria (percent). Source: Interviews with managers of farms, 2017.

The costs for implementation of formal and informal norms, standards, etc. are negative factor for agrarian sustainability according to the majority of managers of Big size holdings $(62,5 \%)$. These farms to a greater extent comply with formal rules, interact with external agents and institutions, and have higher absolute and relative costs of that type. In individual subsectors of agricultural production the negative impact on agrarian sustainability of the costs for implementation of formal and informal norms, standards, etc. is faced to the greatest degree by farms specialized in Mix livestock (all of them), Grazing livestock (two third), and in Vegetables, Flowers, and Mushrooms (every another one). In all these subsectors the size of farms is relatively small, while costs for adaptation to the new standards of the European Union, market counterparts, and nonmarket agents extremely high. To a little extent the negative impact of such costs affects highly standardized and mechanized productions like Pigs, Poultries, and Rabbits ( $0 \%$ ), Field crops, Permanent crops, and Mix crops (one fifth of holdings).

Costs for implementation of formal and informal norms, standards, etc. to a greater extent impact negatively the farms, located in Plain regions of the country $(37,5 \%)$, while in Lessfavorite mountainous $(14,29 \%)$ and non-mountainous (25\%) regions, and in the farms with Lands in protected zones and territories $(14,29 \%)$ the adverse effect of that factor on agrarian sustainability is less important. Similarly, costs for implementation of formal and informal norms, standards, etc. are negative factors for the significant part of farms, situated in North-Central region $(60 \%)$, while in South-East region of the country they are essential only for relatively small fraction of holdings (14,29\%).

Possibilities and restrictions for free contracting are important factors for optimization of the governance of sustainable development according to the interests and initiatives of various private and market agents. For more than a half of surveyed farms
(55\%) existing "possibilities for free contracting" are a positive factors for agrarian sustainability, predominately for economic, and to a smaller extent for social and environmental aspect (Figure 2). The positive impact of that factor is pointed out by farm managers of different type, for which provided real freedom to negotiate conditions and prices of exchange are critical for effective and sustainable development.

At the same time however, every fifth of surveyed farms indicates that "possibilities for free contracting" affect negatively agrarian sustainability or its individual aspects (mostly economic one). That concern commercial holdings of various juridical type, size, production specialization, and locations, all of which suffer from "free contracting" with counterparts. Many of the Bulgarian farms of different type have a high asymmetry of contractual positions (a great unilateral dependency) with dominating buyers and/or sellers - big quasi or monopoly suppliers of materials, energy, water, credits, etc. and/or buyers of agricultural produce and services. Agricultural producers have no real possibility to choose a partner and negotiate prices, terms of payment, amount of damages, etc. in relations with suppliers and buyers. At the same time, farms are not able (too expensive) or willing (lack of alternative supplier or buyer) to protect their interests in legitimate way and therefore constantly suffer by the "provided freedom".

Interviewed managers also point out many examples for contracts violation by public (state, municipal, international) bodies adversely affecting agrarian sustainability. For instance, often negotiated subsidies transferred on time or in a required amount, contracted terms are not fulfilled by local and state authorities, etc. Disputing of such "contracts" through a third part (court, etc.) is too expensive or undesirable for individual producers, due to a high specificity, low efficiency, huge costs and bureaucratic procedures, as well as likelihood for subsequent "punitive actions" by the provider of public services (and sanctioned) state body. 


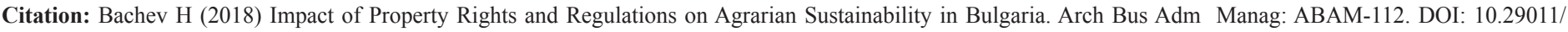
ABAM-112. 100012

For a quarter of interviewed managers existing possibilities for free contracting have no importance for agrarian sustainability or some of its aspects in the contemporary conditions of Bulgarian agriculture.

Quantity and quality of available information of interested agents is essential factor, which predetermine the efficiency of the governance of agrarian sustainability. According to the majority of surveyed managers $(62,5 \%)$ "available information for prices, markets, innovations, etc." Impact positively agrarian sustainability and its different aspects (Figure 2). The favorable effect of the "system of provision" of information for effective governance of agrarian sustainability is indicated by all type of agricultural producers. Different kind of holdings (large, small, individual, group, specialized, not specialized, etc.) have unequal information needs and possibilities for access (collection, purchase, etc.) and processing (skills, qualification, available experts, etc.) of diverse information. Despite that however all underline that external environment work well and information they possess lead to improvement of agrarian sustainability or some of its socioeconomic and environmental aspects.

Only 2,5\% of farms suggest that available information for prices, markets, innovations, etc. is not sufficient or misleading, and therefore is a negative factor for agrarian sustainability. Simultaneously, a good portion of agricultural producers $(35 \%)$ evaluate as neutral the importance of available information for process, markets, innovations, etc. in relation to sustainable agrarian development. Some of the latter holdings (small, subsistence, extensive, etc.) have no great information needs, while another part have no access to information (from media, advisory and training system, consultants, etc.), which is beneficial to the management of their multifunctional activity. Our survey also has found out that many farm managers have none or sufficient reliable information for important parameters related to agrarian sustainability such as: extent of erosion and pollution of soils, quality of ground waters, protected species, biodiversity, etc. in the region or in the area of their farms.

Existing "freedom and restrictions" for formal registration of business forms, joint organizations and associations of agrarian and non-agrarian agents, and associated costs and time of interested parties is one of the major factor for development of efficient private and public modes of governance of agrarian sustainability. According to the majority of surveyed farms existing "possibilities and costs for registration of enterprises, associations, and organizations" at present stage have a little impact on agrarian sustainability or its main aspects (Figure 2). That means that for most managers there are no formal institutional restrictions or high costs and difficulties for registration of various private and collective modes for governing of activity and relations, managing relations with market and private agents, and for lobbying for public support. These farmers of different type assess as "normal" possibilities and costs for registration of private and collective organizations of agricultural producers. Another reason is that majority of Bulgarian farmers rarely participate in a formal registration of any business and other forms (firms, joint ventures, cooperatives, associations, etc.).

A relatively small fraction of interviewed managers $(17,5 \%)$ indicate that existing possibilities and associated costs for registration of farms, associations and organizations affect favorably agrarian sustainability. That group includes managersinnovators looking for new organizational forms for improving activity and actively (and frequently) taking part in procedures for formal registration of various organizational formations. Many of these entrepreneurs are with accumulated experiences in such activity, or use qualified specialists for carrying out formal registrations, and therefore their costs and efforts are not big.

However, a good number of surveyed farms (12,5\%) believe that existing possibilities and costs for registration of farms, associations, and organizations affect negatively agrarian sustainability. Those are usually smaller producers with little experience in formal procedures and/or capability to hire expensive specialists (consultants, lawyers, etc.), for which related institutional restrictions (bureaucratic procedures, high costs of resources and timing, etc.) are obstacle for improving agrarian sustainability or some of its aspects.

Existing formal possibilities for registration and protection of products, origins, activities, etc. and associated costs and time are another important factors for effective development of variety of new forms for governing of agrarian sustainability and its diverse aspects. For the majority of surveyed holdings institutionally determined possibilities (freedom, restrictions) and costs for registration of products, origins, activities, etc. have no significant impact on the governance of agrarian sustainability (Figure 2). That is a consequence of the fact, that most Bulgarian farmers do not formally register new products, origins, trademarks, etc. and therefore think that available possibilities and related costs are important in regards to agrarian sustainability. At the same time, for every forth of the interviewed managers existing "possibilities and costs for registration of products, origins, activities, etc." have a favorable impact on agrarian sustainability and its individual aspects. These are predominately entrepreneurs well familiar with and using formal procedures for official registration of special products, origins, technologies, etc. Along with introduction of the European legislation in the area of registration and protection of agrarian intellectual property in the country gradually are disseminated various forms by private agents and/or farmers organizations (protected products, denominations, origins, bio certification, eco-products and services, etc.). These innovations give new opportunities for increasing efficiency of private and 
collective initiatives and investments, while the lack of bureaucratic obstacles and/or costs, associated with their registration, enhance agrarian sustainability.

Only a tiny proportion of surveyed holdings $(2,5 \%)$ assess as negative the impact of existing possibilities and costs for registration of products, origins, activities, etc. on agrarian sustainability. For some entrepreneurs existing institutional restrictions and costs prevent effective registration of novel products, origins, activities, etc. That is a result of inferior financial capabilities for payment of fees, wages, bribes, etc., insufficient experience and/or expertise for such activity, lack of qualified personnel or practical difficulties, associated with complicated, incomplete and/or vague bureaucratic rules and procedures. The respondents also point out examples when the lack of compulsory certification for certain activities (e.g. production of propagating plants, eco-products, etc.) is a factor for widespread dissemination of inauthentic to declared origin and quality products.

Existing opportunities or obstacles for investment in agriculture and economy as a whole are important factors for improving agrarian sustainability and all its aspects. A quarter of surveyed farm managers evaluate as positive the impact of "possibilities and obstacles for investment" at current stage of development of Bulgarian agriculture (Figure 2). For a relatively little portion of the farms (15\%) possibilities and obstacles for investment in the operating environment, are neutral factors, which neither stimulate nor deter improvement of agrarian sustainability. For the majority of agricultural producers $(60 \%)$ however, real possibilities and obstacles for investment in agrarian sphere obstruct agrarian sustainability and its aspects. For most Bulgarian holdings socio-economic and institutional environment do not provide favorable opportunities for finding investment resources or sufficient incentives for investment activity for increasing economic, social and/or environmental sustainability in the sector.

To the greatest extent existing possibilities and obstacles for investment deter agrarian sustainability in Cooperatives $(83,33 \%)$, holdings with Small sizes $(86,67)$, (all) farms specialized in Vegetables, Flowers and Mushrooms, as well as Pigs, Poultries and Rabbits, farms with Lands in protected zones and territories $(80 \%)$, and located in Less-favored non-mountainous regions $(75 \%)$, as well as in North-Central region of the country (Figure 11). On the other hand, the specific socio-economic and institutional environment to a lesser extent affects adversely the investment activity for improvement agrarian sustainability of Companies $(45,45 \%)$, farms with Big size (12,5\%), holdings specialized in Grazing livestock and Mix livestock $(0 \%)$, and those situated in Mountainous regions (44,44\%), Less-favored mountainous regions $(42,86 \%)$, and in South-East region of the country $(28,57 \%)$.

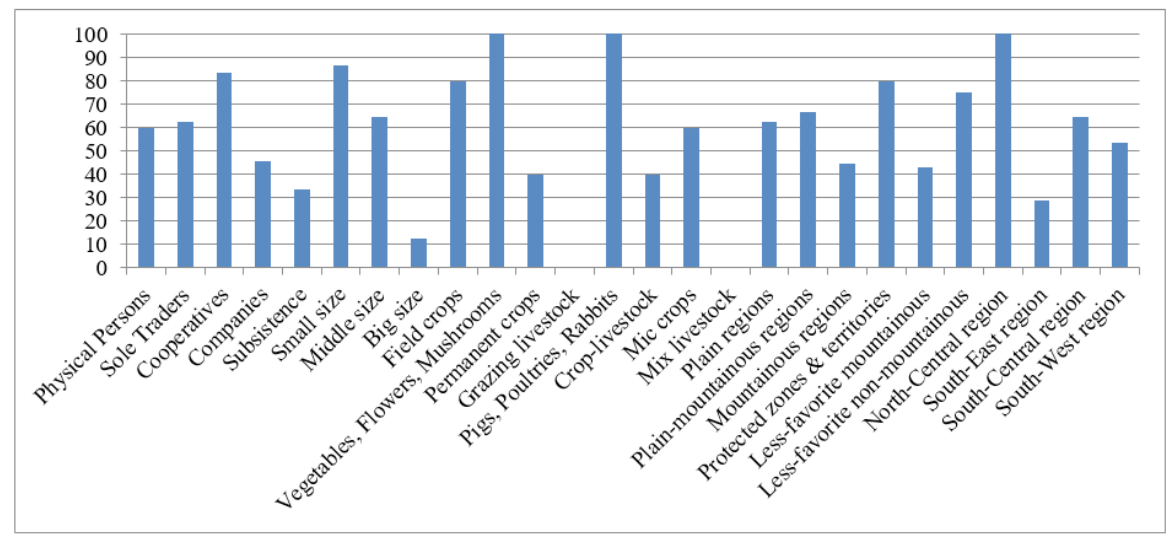

Figure 11: Negative impact of existing possibilities and obstacles for investment on agrarian sustainability in Bulgaria (percent). Source: Interviews with managers of farms, 2017.

Existing monopoly and power positions most often considerably obstruct effective allocation of resources and sustainable development of business organizations, sectors of economy, and individual regions and communities. That is particularly important in agriculture, where producers rarely have monopoly positions - numerous small and competing farms, inefficient national organizations for price negotiation, lack of public prices regulation (guarantee), etc. What is more, very often farms face complete or partial monopoly both in the supply of materials, energy, credit, insurance and other services, as well as in marketing of farm produce.

Our survey has proved that for the majority of the managers of agricultural holdings $(62,5 \%)$ "existing monopoly and power positions" affect negatively agrarian sustainability and its individual aspects (Figure 2). Merely 5\% of all farms asses the actual situation in regards to monopoly as favorable for agrarian sustainability. 
Citation: Bachev H (2018) Impact of Property Rights and Regulations on Agrarian Sustainability in Bulgaria. Arch Bus Adm Manag: ABAM-112. DOI: 10.29011/ ABAM-112. 100012

Such holdings commonly are contractually or completely integrated in some structures with "power" positions and benefit from the monopoly positions of that mode. A significant portion of the managers $(32,5 \%)$ evaluate as neutral existing state regarding presence of monopoly and effects on agrarian sustainability. Such farms either trade on competitive (well working) markets with many sellers and buyers, or most of their relationships are carried with local and predominately small buyers and/or sellers (absence of monopoly).

All categories of holdings, subsectors of agriculture and regions of the country, suffer from the negative impact of existing monopoly and power positions (Figure 12). To the greatest extent the adverse effect of the monopoly and power positions impact agrarian sustainability in Sole Traders (three quarters), holdings with Middle size (78,57\%), farms specialized in Pigs, Poultries and Rabbits, and Mix livestock (by 100\%), as well as Permanent crops (70\%), farms located in Plain-mountainous regions $(73,33 \%)$, Less-favorite mountainous and non-mountainous $(71,43 \%$ and $75 \%$ accordingly), and in North-Central (80\%) and South-West $(71,42 \%)$ regions of the country. On the other hand, the negative effect of monopoly and power positions in regards to agrarian sustainability, to a comparatively lesser degree affects Companies $(45,45 \%)$, farms with Big sizes (37,5\%) and those Predominately for subsistence $(33,33 \%)$, holdings specialized in Field crops and Mix crops (by 40\%), and located in Mountainous regions (55,56\%), and South-East region of the country $(42,86 \%)$.

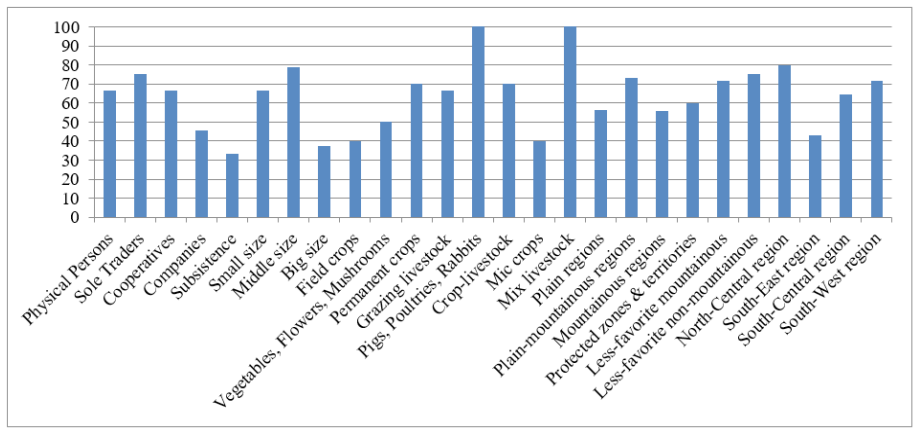

Figure 12: Negative impact of existing monopoly and power positions on agrarian sustainability in Bulgaria (percent). Source: Interviews with managers of farms, 2017.

Personal connections are crucial factor for effective management of relations between different agents. They are particularly important when market mechanisms and private contracts "do not work" and there is no effective public (court) system for enforcement of private contracts and obligations. In the present conditions of Bulgarian agriculture the traditional "personal collections" are still reported as an important positive factor for agrarian agriculture by the great majority $(82,5 \%)$ of interviewed managers (Figure 2). The favorable effect of personal connection for agrarian sustainability is indicated by all type of farms, subsectors of agriculture, and in different regions of the country. Personal links between close friends, relatives, partisans, etc. dominate both in the governance of commercial relations (deals of different type) and various "relations" with public (state, municipal, non-governmental, etc.) organizations, as well as in participation in collective initiatives and/or organizations of different type (marketing, inputs supply, eco-management, lobbying for public support, etc.).

For one tenth of the holdings the personal connections have no importance in the governance of relationships with other agents and in regards to agrarian sustainability. Those are mainly large commercial farms, for which market (prices, competition, trade conditions) rather than personal factors are essential for choosing a partner for exchange and coalition. Comparatively small part of interviewed managers $(7,5 \%)$ indicates that domination of personal connections in Bulgarian agrarian sphere is a negative factor for amelioration of agrarian sustainability and its individual aspects. That type of governance frequently is associated with the privilege and even illegitimate "inclusion" in public support programs or access to major public resources by certain groups and individuals with "good connections" with authority at national, regional and/ or local level.

Building a good reputation is perceived as an important factor contributing to selection of an appropriate supplier, buyer or partner for join initiatives. Therefore, agents having intention to stay a long-time in certain business and improve agrarian sustainability tend to invest in establishment of a "good name". firm or product reputation, etc. On the other hand, created "bad" social reputation gives a good signal for avoiding relations with certain (undesirable) agents and eventually assists the effective governance of agrarian sustainability. According to the majority of surveyed managers $(65 \%)$ established reputation has a positive impact on the governance of agrarian sustainability and its main aspects (Figure 2). The favorable effect of that factor is equally reported by farms of different juridical type, size, production specialization, geographical and ecological location. Simultaneously, none of the investigated holdings suggests that information about/for building a (good, bad) reputation hinders agrarian sustainability.

At the same time however, for a good fraction of holdings (35\%) the established reputation is not a factors affecting agrarian sustainability. The governance of diverse aspects of agrarian sustainability often require relations with new counterparts, for which usually there in no reliable reputation information (new business, regional, or country players, etc.). Therefore agrarian agents use other "faceless" mechanisms for controlling quality and protection of interests as recommendations, collateral, joint investments, short-term contracts, taking additional risk for a higher benefits, etc. 
The state of trust between partners, and agents of a particular kind, in a specific region, subsector of economy, etc. is an $\mathrm{n}$ important factor facilitating relations and cooperation, and leading to realization of socio-economic and environmental objectives of sustainable development. According to the majority of interviewed managers $(60 \%)$ "existing trust" at the contemporary stage of agrarian development have a positive impact on agrarian sustainability and its main aspects (Figure 2). The high trust affects favorably sustainability according to the managers of different type of farms, subsectors of agriculture, geographical and ecological regions of the country.

In agrarian sphere and rural communities a great portion of the relations are between agents, knowing each other well for a long-period of time, and developing trust, reputation and personal connections. Namely such informal mechanisms (trust, good reputation, personal connections, mutual interest to avoid and/or quick resolution of disputes and conflicts, etc.) to a great extent govern effectively a significant part of the activity and determine behavior of the majority of participating agents. Subsequently, a great portion of the agreements in the sector are based on informal contracts, governed by the "high trust" and the "good will" of parties. At the same time, none of the respondents indicates that the extent of trust is a negative factor for agrarian sustainability. That is indicative that those who base their relations on those type (informal) mechanisms appreciate its positive importance in the governance of agrarian sustainability or its aspects.

Nevertheless, for a considerable fraction of the holdings (40\%) existing social trust is a neutral factor for governing agrarian sustainability. At the present stage the agrarian agents increasingly have to trade with unknown counterparts from other regions and/or countries without being able to use traditional interpersonal forms, based on good knowledge, personal connections, punishment through building a bad reputation, etc. What is more, achieving or maintaining agrarian sustainability often requires a long-term efforts and involvements of a big number of participants ("collective actions") in vast territories. The latter gives possibilities for opportunistic behavior of some or most of the participants often leading to a failure of common projects. Many examples are also presented when excess trust to a certain partner(s) in bilateral or multilateral deals lead to failures, nonfulfillment of agreements, unrealized objectives and significant losses for certain parties. All that necessitates in the agrarian sphere increasingly to be used other more efficient forms for governing of agrarian sustainability such as formal contracts and agreements, market competition, assistance of a third party, dispute resolution through a court system, etc.

Evolution of social demands and pressure at national and regional scale is an essential "driving" factor for the pace and character of socio-economic development. However, not always satisfying current social needs leads to accomplishment of multiple goals of sustainable development. The majority of interviewed managers $(62,5 \%)$ believe that "social needs and pressure at national scale" at current stage has no substantial impact for achieving or maintaining agrarian sustainability or any of its aspects (Figure 2). Besides, $15 \%$ of holdings event think that social needs and pressure have a negative outcome regarding agrarian sustainability or its social and/or environmental dimensions.

A good proportion of the managers $(22,5 \%)$ however, have opinion that evolution of social needs, demand for products and services of agrarian sector and pressure of interests groups, government, non-governmental and international organizations, and public at large have a positive significance for realization of agrarian sustainability. Such novel national needs and "pressure" direct (assist, stimulate, sanction) efforts of a considerable part of agricultural producers in line for achieving socio-economic and environmental objectives of sustainable development. Those are predominately bigger commercial farms, which are sensitive to market demand for certain products and services from the consumers in national and/or international scale for socially responsible, environmental friendly, etc. agriculture. There are also numerous good examples for progressive models, introduced by young entrepreneurs, who react to new trends in social needs introducing original initiatives or join novel national or international "movements" for sustainable agriculture (organic agriculture, permaculture, etc.).

As far as "social needs and pressure in the region" is concerned, for the best portion of interviewed managers, they are mostly neutral $(80 \%)$, and even negative factor (10\%) (Figure 2). For every tenth farm however, social needs and pressure in the region is a positive factor for agrarian sustainability, apart from its economic increasingly for the environmental and/or social aspect as well. That concerns mainly smaller holdings which meet local demands and forced greatly to take into account various needs of residents and visitors of the region.

Informal institutions are important factor of the institutional environment, which significantly affect the (transition) process and character of agrarian sustainability. According to 30\%of surveyed managers "informal rules, norms, modes, etc." impact positively agrarian sustainability and its main aspects (Figure 2). In agrarian environment traditionally dominate a great variety of informal rules, norms and forms (contracts, agreements, norms, etc.) which determine greatly relations and behavior of agrarian agents. In the conditions of not well working system of formal institutions, agrarian agents widely use such informal rules and diverse forms for organization and management of entire activity. For a fraction of holdings they also assist the improvement of agrarian sustainability or its individual aspects.

A significant part of the managers asses as neutral the impact of informal rules, norms, forms, etc. on agrarian sustainability. 
Citation: Bachev H (2018) Impact of Property Rights and Regulations on Agrarian Sustainability in Bulgaria. Arch Bus Adm Manag: ABAM-112. DOI: 10.29011/ ABAM-112. 100012

Along with development of the system of formal rules and markets, and improvement of the control and enforcement of formal standards, norms, etc. through lawful way, the formal institutions (greatly) replace informal one in governing relations and behavior of a tiny fraction of agrarian agents. At the same time however, a good portion of holdings (35\%) argue that domination of informal rules, norms, forms, etc. affect adversely agrarian sustainability. A dual system of formal and informal structures in the sector punishes those, who comply with laws and regulations, and favor those violating them. According to the manager of a greenhouse, $90 \%$ of the sector is in the shadow sector where there is no quality and safety control, tax and social security are not paid, etc. That hinders development of the "light" structures and diminishes their competitiveness. In the country still there is no effective system for implementation and enforcement of laws standards, and regulations, as massively are applied informal (even illegal) forms for carrying out activity, conflicts resolution, assets acquisition, access to public resources and support funds, etc. That impedes evolution of the effective (formal) structure for governing of agrarian sustainability and each of its aspects.

All categories of farms, subsectors of agriculture, and regions of the country are exposed to the adverse effect of the informal modes of governance (Figure 13). The only exceptions are Big farms and holdings specialized in Grazing livestock and Mix livestock. In the latter groups the informal institutions "work well" assisting or not disturbing agrarian sustainability and its aspects.

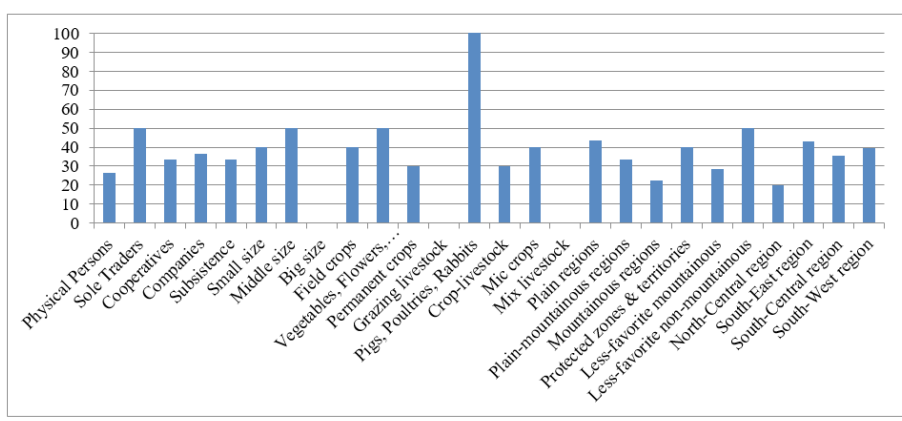

Figure 13: Negative impact of existing informal rules, norms, forms, etc. on agrarian sustainability in Bulgaria (percent). Source: Interviews with managers of farms, 2017.

By the negative impact of the widespread application of informal rules, norms and forms, to the greatest extent are affected Sole Traders $(50 \%)$, farms with Middle size $(50 \%)$, holdings specialized in Pigs, Poultries and Rabbits (100\%), Vegetables, Flowers and Mushrooms (50\%), farms located in the Plain regions $(43,75 \%)$, and in South-East region of the country $(42,86 \%)$. On the other hand, relatively smaller share of Physical Persons (26,67\%), Cooperatives (33,36\%), holdings Predominately for subsistence $(33,33 \%)$, farms specialized in Permanent crops and Mix crop-livestock operation (by 30\%), those located in Plain regions $(22,22 \%)$, and in North-Central region, to a lesser degree evaluate as negative the application of informal rules, norms, forms, etc. In these groups of holdings, subsectors and regions the official rules and forms dominate while informal rules either are not employed or their implementation is neutral or more efficient (cheap, favorable) for participating agents.

Official status of the region (rural, national park, resort, etc.), where a particular farm or agricultural production is located, often provides some socio-economic, institutional and natural advantages for farmers generally or in certain subsectors. For the biggest fraction of holdings $(52,5 \%)$, the "official status of the region" is not essential for agrarian sustainability since they are not located in such regions or their situation does not give any benefits, or it is associated with additional costs (Figure 2). Nevertheless, according to a good portion of interviewed managers $(35 \%)$ the region's official status is a positive factor for agrarian sustainability or some of its aspects. The latter equally concerns farms of different juridical type, sizes, production specialization, ecological and geographical location. Usually farm's location in favorable (resort, more developed, border, etc.) regions gives a number of socio-economics advantages like superior prices, guaranteed marketing, diversification in related and other activities (restaurant, hotel, ecosystem services, tourism, etc.). On the other hand, location of the holding in special (rural, less-favored, protected zones and territories, etc.) region gives opportunities for participation in various public support schemes and leads to improvement of agrarian sustainability. Nevertheless, for a good proportion of farms $(12,5 \%)$, the special status of the region have a negative impact on agrarian sustainability or individual aspects. Affiliation of the farm to such a region most often is associated with numerous comparative disadvantages (low productivity, superior costs, remoteness from markets, restrictions for resources utilization and certain activities, etc.), which are not compensated or insufficiently offset through public support forms, and eventually compromise agrarian sustainability or some of its aspects.

Climate changes are important factor for agrarian sustainability and often discussed in recent years as affecting positively, negatively or neutrally agricultural producers and agrarian sustainability. Our study has found out that according to the majority of surveyed farms $(60 \%)$ "climate changes" are a negative factor in regards to agrarian sustainability, and its economic, social and environmental aspects (Figure 2). A great part of Bulgarian farms are not prepared or able to adapt to climate changes (warming, draughts, natural extremes, floods, etc.) though appropriate changes in production structure, technologies, organizational and governing forms. All that diminishes agrarian sustainability and its individual aspects. Some managers point out that bad "management" such as incorrect zoning, agro-techniques, etc., additionally strengthened (or caused) adverse impacts of climate. For instance, the best conditions for production of valuable 
(“expensive") apples are not in Pazarjik region (200 m above sea level), but at a higher grounds $(600 \mathrm{~m})$; Tracian lowland is ideal for fruits and vegetables, rather than widespread wheat and corn cultivation, broadly practiced zero or insufficient irrigation cannot offset changed needs and lead to adverse climate impact, etc.

Only $5 \%$ of interviewed managers report that climate changes affect positively agrarian sustainability. Some farmers are obviously favored from the climate changes as warming, drought, heavy rainfalls, etc. For that type of holdings climate changes are associated with amelioration of conditions, yields growth, prolong of agro-techniques period, and possibility to produce new crops and/or diversify in new activities. For a good portion of Bulgarian farms $(35 \%)$, climate changes are not important in relation to agrarian sustainability. The managers of the latter holdings believe that such changes are not new and threaten agriculture abnormalities (rather a normal process of fluctuations) and that farms possess sufficient adaptation capability for counteraction to changes, or holdings are somehow favored from the novel trends in climate evolution.

Climate changes to the greatest extent affects negatively Cooperatives $(100 \%)$ and Companies $(72,73 \%)$, large and as a rule highly specialized enterprises $(100 \%)$, holdings in Field crops $(100 \%)$ and Permanent crops $(80 \%)$, farms with Lands in protected zones and territories $(100 \%)$, those located on Lessfavored mountainous regions $(85,71 \%)$, as well as in South-East region of the country $(85,71 \%)$ (Figure 14$)$. On the other hand, the adverse impact of climate changes on agrarian sustainability is not felt by none among farms specialized in Grazing livestock, and Pigs, Poultries, and Rabbits. To a lesser degree under the influence of climate changes are holdings specialized in Vegetables, Flowers and Mushrooms, widely using greenhouses, as well as holdings located in Less-favored non-mountainous regions (by 25\%).

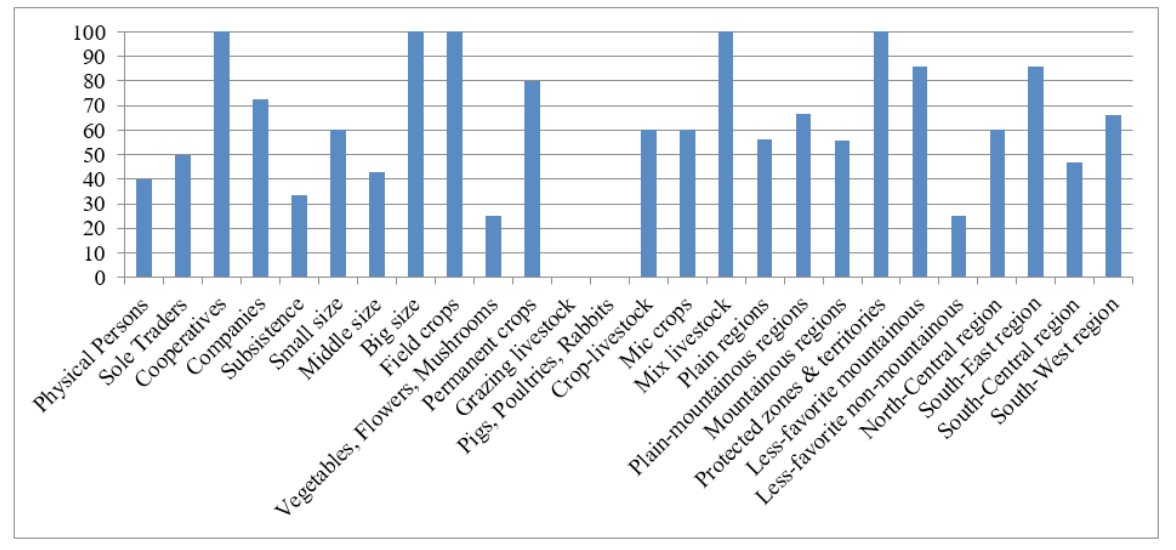

Figure 14: Negative impact of climate changes on agrarian sustainability in Bulgaria (percent). Source: Interviews with managers of farms, 2017.

Holdings of Physical Persons (40\%) are affected less negatively by climate changes comparing to other juridical types. Also holdings Predominately for subsistence $(33,33 \%)$ and with Middle sizes $(42,25 \%)$ are less sensitive to adverse consequences of climate changes. Similarly, a smaller share of the farms located in Mountainous regions (55,56\%) are adversely affected by climate changes in comparison with holdings in Plain and Plain-mountainous regions. Also smaller number of agricultural producers in South-Central region of the country $(47,06 \%)$ assesses as negative the impact of climate changes comparing to farms in other regions of the country.

Analysis of the relationships between agrarian sustainability level in the farms, and the importance that managers give to the individual elements of external environment and governing modes, also allow evaluating the actual efficiency of different governing mechanisms and modes for improving agrarian sustainability in the country. In regards to most components of the external institutional, market and natural environment there is no a strong correlation between the good and high levels of sustainability and the (positive, negative) assessments of managers for the impact of corresponding factors on agrarian sustainability (Figure 15). The only exceptions are "free access to public lands" $(93,33 \%)$, "established reputation" (92,31\%), and "existing trust" (91,67\%), where the farms with a positive estimates for the impact of factors demonstrate also superior levels of agrarian sustainability. Apparently, for the rest elements of external environment, the farms adapt to conditions for achieving agrarian sustainability, independent of the favorable or adverse impact of considered factors. 


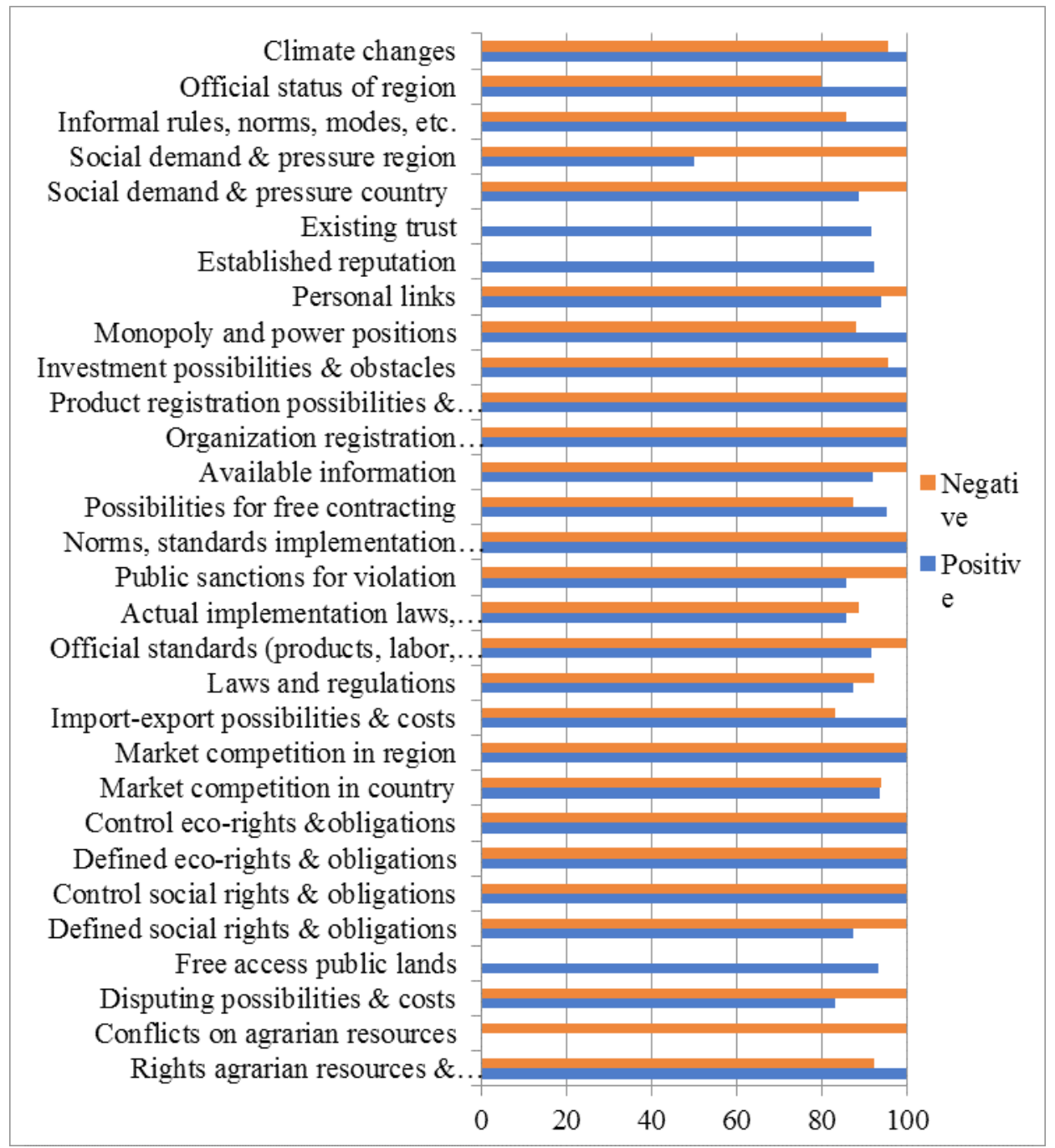

Figure 15: Share of farms with good and high sustainability, which evaluate as positive or negative the impact of external environment in Bulgaria (percent). Source: Interviews with managers of farms, and assessment of sustainability of agricultural farms, 2017.

\section{Conclusion}

Implemented first of a kind empirical study on impact of diverse elements of socio-economic, market, institutional and natural environment on agrarian sustainability made it possible to identify and assess the factors of "external" environment, mostly affecting agrarian sustainability in the country, and in individual subsectors of agriculture, geographical and administrative regions, (agro) ecosystems, and type of farming enterprises. Our study has found out that individual elements of external institutional, market and natural environment affect quite unequally farms of different types, individual subsectors of agriculture, and specific ecological and geographical regions.

Nevertheless, evolution of the system of governance and the level of agrarian sustainability depends on various economic, political, behavioral, demographic, technological, international, natural etc. factors as well as dominating market, private, collective, public, etc. modes of governance applied by agents. Separate and joint effects of all these important factors are to be accounted for and assessed in further research in that new area. Besides, always there is a certain "time lag" between the "improvement" of the governance system, and the change in agents behavior, and the positive, negative or neutral impact on the state of agrarian sustainability, and its individual aspects. All these factors are to be studied in further studies as estimates also made on the "dynamics" of impact over a longer time horizon. 
Citation: Bachev H (2018) Impact of Property Rights and Regulations on Agrarian Sustainability in Bulgaria. Arch Bus Adm Manag: ABAM-112. DOI: 10.29011/ ABAM-112. 100012

Having in mind the importance of comprehensive assessments of the impacts of institutional environment on agrarian sustainability, and the enormous benefits for the farm management and agrarian policies, this type of studies are to be expended and their precision and representation increased. The latter however, requires a close cooperation between all interested parties, and participation of the farmers, agrarian organizations, local and central authorities, interest groups, research institutes and experts, etc. Moreover, estimates precision has to be improved, and besides on the assessments of farm managers to incorporate other relevant information - expertise, studies on "actual" behavior of various agrarian and associated "effects", report, statistical, etc. data.

\section{References}

1. North DC (1990) Institutions, Institutional Change and Economic Performance, Cambridge University Press.

2. Williamson O (1996) The Mechanisms of Governance. Oxford University Press.

3. Bachev H (2010) Governance of Agrarian Sustainability. Nova Science Publishers.

4. Bachev H (2010) Management of Farm Contracts and Competitiveness, Framework for analysis, Case of Bulgaria.

5. Bachev H (2016) Defining and Assessing the Governance of Agrarian Sustainability. Journal of Advanced Research in Law and Economics VII: 797-816.

6. Bachev H, Ivanov B, Toteva D, Sokolova E (2016) Agrarian Sustainability and its Governance - Understanding, Evaluation, Improvement. Journal of Environmental Management and Tourism 7: 639-663.

7. Bachev H, Ivanov B, Toteva D, Toteva E (2017) Agrarian sustainability in Bulgaria - economic, social and ecological aspects. Bulgarian Journal of Agricultural Science 23: 519-525.

8. Raman S (2006) Agricultural Sustainability. Principles, Processes and Prospect. New York The Haworth Press Inc.

9. Sauvenier X, Valekx J, Van Cauwenbergh N, Wauters E, Bachev H, et al. (2005) Framework for Assessing Sustainability Levels in Belgium Agricultural Systems - SAFE, Belgium Science Policy Brussels.

10. Terziev D, Radeva D (2016) Studying the New Agriculture. 2nd International Conference on Development and Economics (I.CO.D.ECON.), Thessaloniki, Greece: Conference proceedings.

11. UN (1992) Report of the United Nations Conference on Environment and Development. 3-14 June 1992, Rio de Janeiro United Nation.
12. UN (2015) Paris Climate Change Conference - November-December 2015.

13. Bachev H (2002) Study on Land Supply in Bulgarian Farms. Farm Management and Rural Planning 3: 189-203.

14. Bachev H (2003) Study on Labor Supply in Bulgarian Farms. Farm Management and Rural Planning 4: 129-145.

15. Bachev H (2009) Mechanisms of Governance of Agro-Ecosystem Services, Achieving Environmental Security: Ecosystem Services and Human Welfare, IOS Press, Amsterdam 31-52.

16. Bachev H (2011) Water Governance in Bulgarian Agriculture, Climate Change and its Effects on Water Resources, Issues of National and Global Security, Springer Science+Business Media B V: 215-224.

17. Bachev H (2014) Environmental Management in Agriculture, Mechanisms Forms and Efficiency, LAP LAMBERT Academic Publishing.

18. Bachev H (2017) Sustainability Level of Bulgarian Farms. Bulgarian Journal of Agricultural Science 23: 1-13.

19. Bachev H (2018) Impact of Institutional Environment on Agrarian Sustainability in Bulgaria. Economic Thought 4: 33-60.

20. Bachev H (2018) The Sustainability of Farming Enterprises in Bulgaria, Cambridge Scholars Publishing.

21. Bachev H, Kagatsume M (2002) Governing of Financial Supply in Bulgarian Farms. The Natural Resource Economics Review, No 8, Kyoto University, Kyoto 131-150.

22. Bachev H, Kagatsume M (2003) Governing of Output Realization in Bulgarian Farms. The Natural Resource Economics Review 9: 55-69.

23. Bachev H, Tsuji M (2001) Structures for Organization of Transactions in Bulgarian Agriculture. Journal of the Faculty of Agriculture of Kyushu University No 46: Fukuoka 123-151.

24. Bachev H, Terziev D (2017) Environmental Sustainability of Agricultural Farms in Bulgaria. Journal of Environmental Management and Tourism 8: 968-994.

25. Bachev H, Terziev D (2018) A Study on Agrarian Sustainability Impact of Governance Modes in Bulgaria. Journal of Applied Economic Sciences XIII.

26. Bachev H, Nanseki T (2008) Environmental Management in Bulgarian Agriculture - Risks, Modes, Major Challenges, Journal of the Faculty of Agriculture of Kyushu University No 53: 363- 373. 